\title{
TITLE:
}

\section{COLLATERAL CONSTRAINTS AND THE CURRENT ACCOUNT: THEORY AND EVIDENCE}

\section{$\operatorname{AUTHOR}(S)$ :}

Kunieda, Takuma; Okada, Keisuke; Shibata, Akihisa

\section{CITATION:}

Kunieda, Takuma ...[et al]. COLLATERAL CONSTRAINTS AND THE

CURRENT ACCOUNT: THEORY AND EVIDENCE. Economic Inquiry 2016, 54(1): 633-651

\section{ISSUE DATE:}

2016-01

URL:

http://hdl.handle.net/2433/217905

\section{RIGHT:}

This is the accepted version of the following article: [Kunieda, T., Okada, K. and Shibata, A. (2016), COLLATERAL CONSTRAINTS AND THE CURRENT ACCOUNT: THEORY AND EVIDENCE. Economic Inquiry, 54: 633-651.], which has been published in final form at https://doi.org/10.1111/ecin.12251. This article may be used for non-commercial purposes in accordance with Wiley Terms and Conditions for Self-Archiving.; This is not the published version. Please cite only the published version.; この論文は出版社版でありません。引用の際には出版社版をご確認ご利用ください。 


\title{
COLLATERAL CONSTRAINTS AND THE CURRENT ACCOUNT: THEORY AND EVIDENCE*
}

\author{
Takuma Kunieda ${ }^{\dagger}$ \\ Keisuke Okada \\ Akihisa Shibata ${ }^{\S}$ \\ Kwansei Gakuin University \\ Kansai University \\ Kyoto University
}

January 24, 2017

\begin{abstract}
We investigate the impact of domestic financial frictions on the current account dynamics in Asian countries before and after the Asian financial crisis in 1997-1998 by introducing collateral constraints into the intertemporal current account approach. We examine six Asian countries. Before the crisis, collateral constraints significantly impact the current account in Korea, Malaysia, the Philippines, and Thailand, but after the crisis, they do not. Our study shows that the impact of domestic financial frictions on the current account changes before and after a financial crisis. (JEL F32, F41)
\end{abstract}

${ }^{*}$ This work has received financial support from City University of Hong Kong (No. 7004283), JSPS Grant-in-Aid for Young Scientists (B) (No. 26780163), JSPS Grant-in-Aid for Scientific Research (B) (No. 15H03354), JSPS Grant-in-Aid for Specially Promoted Research (No. 23000001), JSPS Grant-in-Aid for Scientific Research (B) (No. 23330060), and the Joint Research Program of KIER. We would like to express special thanks to an anonymous referee and Bruce McGough, who is a co-editor, for their invaluable comments and suggestions. We are also grateful to seminar participants at Kyoto University for their comments. All remaining errors, if any, are ours.

${ }^{\dagger}$ Corresponding author. School of Economics, Kwansei Gakuin University, 1-155 Uegahara Ichiban-Cho, Nishinomiya, Hyogo, 662-8501, JAPAN, Phone: +81 79854 6482, Fax: +81 79851 0944, E-mail: tkunieda@kwansei.ac.jp

${ }^{\ddagger}$ Faculty of Economics, Kansai University, 3-3-35 Yamate-cho, Suita-shi, Osaka 564-8680, JAPAN, Phone: +81-6-6368-0623, Fax: +81-6-6339-7704, E-mail: k_okada@kansai-u.ac.jp

${ }^{\S}$ Institute of Economic Research, Kyoto University, Yoshida-Honmachi, Sakyo-ku, Kyoto 606-8501, JAPAN, Phone: +81-75-753-7126, Fax: +81-75-753-7198, E-mail: shibata@kier.kyoto-u.ac.jp 


\section{INTRODUCTION}

Over the past twenty-five years, the importance of financial frictions has drawn attention from many researchers aiming to understand macroeconomic phenomena such as economic growth and business cycles. ${ }^{1}$ Despite such attention from researchers, however, few studies have conducted statistical testing to determine whether macroeconomic models with financial frictions can actually be applied to real economies. ${ }^{2}$ In this paper, by developing a small open economy version of Kiyotaki and Moore's (1997) model following Kasa (1998), we derive a closed-form solution for the current account dynamics. By using only macroeconomic data, we directly estimate the closed-form solution to examine the performance of the Kiyotaki and Moore model in six Asian countries: Indonesia, Korea, Malaysia, the Philippines, Singapore, and Thailand.

Many Asian and Latin American countries experienced financial crises in the mid-1990s. The six Asian countries that we study had a devastating financial crisis in 1997-1998 (the Asian financial crisis). According to Bernanke (2005), it is highly likely that the pattern for the current account dynamics in many Asian and Latin American countries changed in the mid-1990s. Before the crisis, they had been net capital importers, but they became net capital exporters after the crisis. The change in the current account positions of these countries in the mid-1990s is one of the causes driving global imbalances in the 2000s. As such, it is important to analyze the determinants of the current account dynamics in Asian countries. However, few empirical studies focus on collateral constraints as a determinant of

\footnotetext{
${ }^{1}$ Many researchers have emphasized financial frictions as an important factor in understanding macroeconomic phenomena. In the literature on finance and economic growth, Galor and Zeira (1993) and Aghion et al. (2005), among others, theoretically demonstrate that relaxing financial frictions promotes economic growth. In the literature on business cycles and financial frictions, Bernanke and Gertler (1989), Kiyotaki and Moore (1997), Cordoba and Ripoll (2004), and Pintus and Wen (2013) study the financial accelerator mechanism and investigate how and how much the effects of productivity shocks on macroeconomic activities are amplified. Moreover, Matsuyama (2007, 2013), Kikuchi (2008), Kikuchi and Stachurski (2009), Kunieda and Shibata (2011, 2014), and Myerson (2012) derive endogenous business fluctuations caused by financial frictions.

${ }^{2}$ There are many studies that evaluate dynamic stochastic general equilibrium (DSGE) models with financial frictions by calibrating them and comparing their first and second order moments with the actual data.
} 
the current account. ${ }^{3}$ In addition to examining the performance of the Kiyotaki and Moore model in the six Asian countries, we investigate whether the impact of domestic collateral constraints on the current account changed from before and to after the Asian financial crisis by applying the closed-form solution.

Our empirical results from the six Asian countries show that among these six countries, Korea, Malaysia, the Philippines, and Thailand show an almost identical structural change with respect to the impact of collateral constraints on the current account at the time of the financial crisis: only before the crisis do collateral constraints in these four countries significantly impact the current account; after the crisis, they do not. This outcome implies that the Kiyotaki and Moore model can be applied to these four countries before the crisis.

Our basic theoretical model is deterministic: no stochastic shocks affect production functions. In the closed-form solution, if an economy does not face a collateral constraint, the current account is only determined by the one-period-lagged current account, the first difference in net output, and the first difference in foreign reserves. However, if an economy faces a collateral constraint, the one-period-lagged first difference in private credit also affects the current account. If the coefficient of the one-period-lagged first difference in private credit is significantly negative, an economy faces a collateral constraint and Kiyotaki and Moore's (1997) model can be applied to the economy.

Although the closed-form solution for the current account in the deterministic model is simple, an economy may be subject to stochastic productivity shocks. Therefore, we extend the deterministic model to a stochastic version by introducing an aggregate shock in the production technology and derive a closed-form solution for the current account in the stationary state, in which all variables exhibit stationary distributions. As in the deterministic model, if an economy does not face a collateral constraint, the current account is only determined by the aforementioned three factors. In contrast with the deterministic model, however, if an economy faces a collateral constraint, the current period first difference in

\footnotetext{
${ }^{3}$ Notable exceptions are Kasa (1998) and Kunieda and Shibata (2005) as discussed in section VI.
} 
private credit negatively affects the current account in addition to the other three determinants. ${ }^{4}$ The estimation results from the stochastic closed-form solution are almost the same as those obtained from the deterministic closed-form solution.

Corsetti et al. (1999) document the causes of the Asian financial crisis. In their study, there are three key concepts that characterize the eve of the financial crisis: overlending, current account imbalances, and the maturity structure of capital inflows. According to their study, the fragile banking and financial systems in Asian countries led to overlending booms in these countries prior to the financial crisis. For example, in Thailand, although government regulation limited the credit provision of traditional commercial banks, unregulated nonbank financial intermediaries, which had emerged after the financial liberalization of the 1990s, circumvented credit limits. Furthermore, a tax deduction incentivized these nonbank financial intermediaries to commit to offshore borrowing. As a result, these intermediaries substantially expanded their lending to the real estate sector, primarily financed by offshore borrowing. ${ }^{5}$ Massive capital inflows in Asian countries due to the large expansion of offshore borrowing induced large current account deficits. Under these circumstances, there was a double misalignment problem in these countries in which unproductive domestic long-term investment projects were financed by short-term borrowing with a foreign currency. Foreign lenders with short lending maturity anticipated the failure of unproductive investment projects and the insolvency of these countries and therefore refused to renew lending, causing the Asian financial crisis.

Given the numerous capital inflows and overlending to these countries, one might raise a natural question: did borrowers in Asian countries really face collateral constraints? Although we investigate this question in this paper using macroeconomic data, there are some

\footnotetext{
${ }^{4}$ If considering an identity of the current account, one might argue that it is obvious that the current period first difference in private credit negatively affects the current account; however, the closed-form solution derived from the stochastic model is not an identity of the current account, and productivity shocks in the stationary state change the constrained borrowers' behavior in terms of consumption and investment in land, which affects the current account through the financial markets.

${ }^{5}$ Corsetti et al. (1999) provide evidence for the stock market prices of the property sector that is consistent with speculative overinvestment in land and real estate in Asian countries during the 1990-1996 period; this overinvestment boosted land and real estate prices. See Table 11 in Corsetti et al. (1999).
} 
pieces of microeconomic evidence indicating that borrowers faced collateral constraints before the financial crisis. Using banking data covering the period 1992-1996, Menkhoff et al. (2006) provide evidence showing that collateral-based lending is prevalent in Thailand. Similarly, using firm level data, Charumilind et al. (2006) reveal that not only relationship lending but also collateral-based lending were present in long-term loan contracts in Thailand before the Asian financial crisis. Moreover, Driffield and Pal (2001) investigate firm level data during the 1989-1997 period for Indonesia, Korea, Malaysia, and Thailand and find evidence suggesting that smaller firms in these countries were credit constrained. ${ }^{6}$ Although using microeconomic data, as done in these studies, appears to be suitable for addressing whether the private sector suffers from collateral constraints, we would incur a great cost if we examined many countries using microeconomic data for each and it appears to be impossible to investigate the effect of collateral constraints on the current account dynamics using microeconomic data. Given this situation, our simple macroeconomic estimation merits application to examine whether an economy faces collateral constraints, and it complements the microeconomic estimations performed by the aforementioned studies.

The remainder of this paper is organized as follows. In the next section, we present a dynamic general equilibrium model and derive an estimable closed-form current account solution. In section III, we describe the data, and in section IV, we obtain the estimation results for the six Asian countries. In section V, we extend the deterministic model derived in section II to a stochastic model and obtain estimation results similar to those in section IV. In section VI, we discuss the related literature. We provide our concluding remarks in section VII.

\section{Model}

\footnotetext{
${ }^{6}$ Although they do not explicitly examine the presence of collateral-based lending, they find evidence for credit constraints in these countries. According to Berger and Udell (2002), there are at least four primary lending technologies for financial intermediaries - financial statement lending, asset-based lending, credit scoring, and relationship lending. These four lending technologies are not mutually exclusive in a country, and collateral constraints relate to asset-based lending. These four lending technologies are institutional, meaning that they have been developed over the years, and thereby, if asset-based lending is one of the primary lending technologies causing credit constraints in Asian countries, the massive capital inflows and overlending on the eve of the financial crisis must be associated with collateral constraints.
} 
The structure of the model economy is based on Kunieda and Shibata (2005), which is an extension of Kasa (1998). A country is assumed to be a small open economy facing a world interest rate. The economy consists of savers and borrowers. As in Kiyotaki and Moore's (1997) model, the borrowers are collaterally constrained. The total population in the economy is normalized to one, and the ratio of borrowers to savers is $\lambda: 1-\lambda$, where $\lambda \in(0,1)$ is a constant. All of the borrowers are identical in that they have the same preference and technology. Similarly, all of the savers are identical in these two characteristics. The instantaneous utility functions of both savers and borrowers are assumed to be identical; specifically, these are given by $\ln c_{t}^{*}$ and $\ln c_{t}$, where $c_{t}^{*}$ and $c_{t}$ are the consumption of a saver and of a borrower, respectively.

\section{$\underline{\text { Savers }}$}

Each saver is endowed with two types of production technologies. While both of the production technologies create a consumption good, their inputs are different. One uses land $\left(x^{*}\right)$ as input and the production function is given by

$$
G_{1}\left(x_{t}^{*}\right)
$$

where $G_{1}^{\prime}>0$ and $G_{1}^{\prime \prime}<0 . G_{1}$ satisfies the Inada conditions: $\lim _{x^{*} \rightarrow 0} G_{1}^{\prime}()=.\infty, \lim _{x^{*} \rightarrow \infty} G_{1}^{\prime}()=$. 0 , and $G_{1}(0)=0$. The other technology uses capital $\left(k^{*}\right)$ as input, and the production function is given by

$$
G_{2}\left(k_{t}^{*}\right)
$$

where $G_{2}^{\prime}>0$, and $G_{2}^{\prime \prime}<0 . G_{2}$ also satisfies the Inada conditions. Because each saver is endowed with the two types of technology, his output at time $t+1$ is given as follows:

$$
y_{t+1}^{*}=G_{1}\left(x_{t}^{*}\right)+G_{2}\left(k_{t}^{*}\right),
$$

where we note that production takes one gestation period. A saver with a discount factor 
$\beta \in(0,1)$ solves the following maximization problem:

$$
\begin{array}{ll} 
& \max \sum_{t=0}^{\infty} \beta^{t} \ln c_{t}^{*} \\
\text { s.t. } & c_{t}^{*}+q_{t}\left(x_{t}^{*}-x_{t-1}^{*}\right)+I_{t}^{*}+R b_{t-1}^{*} \\
& =(1-\tau)\left[G_{1}\left(x_{t-1}^{*}\right)+G_{2}\left(k_{t-1}^{*}\right)\right]+b_{t}^{*},
\end{array}
$$

where $I_{t}^{*}=k_{t}^{*}-(1-\delta) k_{t-1}^{*} ; b_{t}^{*}$ is debt if positive or assets if negative; $q_{t}$ is the land price; and $R$ is the gross world interest rate, which is constant and assumed to be greater than one. Eq. (1) is the saver's lifetime utility, and Eq. (2) is his flow budget constraint. Note that the government imposes an income tax to finance its spending and purchase of foreign reserves in each period, and $\tau$ is a constant tax rate, which is exogenously determined by the government.

The first-order conditions for the saver are given by the following:

$$
\begin{aligned}
& c_{t+1}^{*}=\beta R c_{t}^{*} \\
& \frac{(1-\tau) G_{1}^{\prime}\left(x_{t}^{*}\right)}{u_{t}}=R \\
& (1-\tau) G_{2}^{\prime}\left(k_{t}^{*}\right)=R+\delta-1,
\end{aligned}
$$

where $u_{t}=q_{t}-q_{t+1} / R$. Eq. (3) is the Euler equation, and Eqs. (4) and (5) are the intratemporal optimality conditions in the land and capital markets, respectively. ${ }^{7}$ The necessary and sufficient conditions for the optimality of this maximization problem consist of Eqs. (3)(5) as well as the transversality condition. It is noted that $k_{t}^{*}$ is constant throughout all time periods, whereas $x_{t}^{*}$ varies according to the land price.

\section{Borrowers}

Each borrower is endowed with a linear production technology, $y_{t+1}=a x_{t}$ that takes land as

\footnotetext{
${ }^{7}$ To be accurate, to ensure that all savers remain savers over their lifetimes, the assets that they hold in the steady state $\left(-\hat{b}^{*}\right)$ must be greater than zero. As seen later, $-\hat{b}^{*}$ is given by $-\hat{b}^{*}=\left[\delta \hat{k}^{*}-(1-\tau)\left(G_{1}\left(\hat{x}^{*}\right)+\right.\right.$ $\left.\left.G_{2}\left(\hat{k}^{*}\right)\right)\right] /(R-1)$, where $\hat{x}^{*}=G_{1}^{\prime-1}(R \beta a)$ and $\hat{k}^{*}=G_{2}^{\prime-1}((R+\delta-1) /(1-\tau))$ are the land and capital stocks, respectively, held by a saver in the steady state. We impose parameter conditions so that $-\hat{b}^{*}>0$.
} 
its input. ${ }^{8}$ Here, $a, x_{t}$, and $y_{t+1}$ represent a constant productivity parameter, land held by the borrower at time $t$, and her output at time $t+1$, respectively. While a borrower borrows resources from the financial market, she faces a credit constraint associated with the value of the collateral in each period. Following Kiyotaki and Moore (1997), technical conditions are imposed on the parameters:

$$
a>R \beta a>G_{1}^{\prime}((1-R \beta) \bar{X} /(1-\lambda)),
$$

where $\bar{X}$ is the total amount of land. Through Eq. (6), we exclude economically meaningless solutions from the model.

A borrower with a discount factor $\beta \in(0,1)$ maximizes her lifetime utility as follows:

$$
\begin{array}{ll} 
& \max \sum_{t=0}^{\infty} \beta^{t} \ln c_{t} \\
\text { s.t. } \quad & c_{t}+q_{t}\left(x_{t}-x_{t-1}\right)+R b_{t-1}=(1-\tau) a x_{t-1}+b_{t}, \\
& b_{t} \leq R^{-1} q_{t+1} x_{t},
\end{array}
$$

where Eqs. (8) and (9) represent the flow budget constraint and the credit constraint, respectively, and again $\tau$ is the constant tax rate imposed on her income. The online appendix demonstrates that there exists time $T$ such that from time $T$ onward, the credit constraints given by Eq. (9) are always binding. Henceforth, we focus on a case where the credit constraints are always binding.

The first-order conditions for the borrower are given by the following:

$$
\begin{aligned}
& \frac{1}{c_{t}}-\beta R \frac{1}{c_{t+1}}-\phi_{t}=0 \\
& -\frac{q_{t}}{c_{t}}+\beta\left[(1-\tau) a+q_{t+1}\right] \frac{1}{c_{t+1}}+R^{-1} q_{t+1} \phi_{t}=0,
\end{aligned}
$$

\footnotetext{
${ }^{8}$ For simplicity, it is assumed that each borrower is endowed with only one production technology that takes land as its input. One can imagine that while each borrower could access another production technology that is linear with respect to capital, when the borrowers use this technology, its productivity would be extremely low compared to the world interest rate.
} 
where $\phi_{t}$ is a co-state variable of the credit constraint at time $t$. The necessary and sufficient conditions for the optimality of this maximization problem consist of Eqs. (10) and (11) as well as the transversality condition.

\section{Government}

As in Jeanne and Rancière (2011), we introduce foreign reserves into the current model because the build-up of foreign reserves after the Asian financial crisis is an important factor determining the current account dynamics. ${ }^{9}$ We assume that the tax revenue collected by the government is used for public spending and the purchase of foreign currencies. The government runs a balanced budget in each period, and the government budget constraint is given by

$$
\tau\left[\lambda y_{t}+(1-\lambda) y_{t}^{*}\right]=g_{t}+F R_{t}-R \times F R_{t-1}
$$

where $g_{t}$ and $F R_{t}$ are government spending and foreign reserves, respectively. We assume that the interest rate on foreign reserves is the same as the world interest rate. Government spending $\left(g_{t}\right)$ is exogenously determined by the government.

\section{Equilibrium}

A competitive equilibrium in this small open economy with world interest rate $R$ is expressed by sequences of a land price, $\left\{q_{t+1}\right\}$, and allocation, $\left\{\left(c_{t}^{*}, c_{t}\right),\left(x_{t}^{*}, x_{t}\right),\left(b_{t}^{*}, b_{t}\right), k_{t}\right\}$ for $t \geq 0$, so that the savers' and borrowers' optimization conditions hold, and the land market clears. ${ }^{10}$

The saver's lifetime utility is log-linear, and thus his optimal consumption is derived as follows:

$$
c_{t}^{*}=(1-\beta)\left[(1-\tau) y_{t}^{*}-I_{t}^{*}+q_{t} x_{t-1}^{*}-R b_{t-1}^{*}+\sum_{j=0}^{\infty} R^{-j} \pi_{t+j}\right],
$$

where $\pi_{t}=(1 / R)\left((1-\tau) y_{t+1}^{*}-I_{t+1}^{*}\right)-u_{t} x_{t}^{*}$.

\footnotetext{
${ }^{9}$ Jeanne and Rancière (2011) derive the optimal level of foreign reserves and suggest that the recent build-up of foreign reserves in emerging Asian economies exceeds the level required by an insurance motive against sudden stops. We do not consider the optimal level of foreign reserves in the current model.

${ }^{10}$ As demonstrated by Kunieda and Shibata (2005), an equilibrium exists and is uniquely determined under the parameter conditions assumed in Eq. (6).
} 
Because Eq. (9) is binding, the budget constraint of a borrower, Eq. (8), is reduced to

$$
c_{t}+u_{t} x_{t}=(1-\tau) a x_{t-1}
$$

From Eqs. (10) and (11), we obtain a new Euler equation:

$$
c_{t+1}=\frac{(1-\tau) a \beta}{u_{t}} c_{t}
$$

From Eqs. (14) and (15), the borrower's optimal consumption is obtained as follows:

$$
c_{t}=(1-\beta)\left[(1-\tau) a x_{t-1}+q_{t} x_{t-1}-R b_{t-1}\right]=(1-\beta)(1-\tau) a x_{t-1} .
$$

\section{Proposition 1}

Suppose that $\hat{x}$ is the land held by borrowers in the steady state, and $Z$, a so-called net output, is defined by the output minus the sum of investment and government spending. Then, the closed-form solution for the current account dynamics around the steady state of the economy is given as follows:

$$
C A_{t}=\beta R C A_{t-1}+(1-\beta) \Delta F R_{t}+\beta \Delta Z_{t}-(1-\beta) \Psi \lambda \hat{x} \Delta P C_{t-1},
$$

where $C A, P C$, and $\Psi$ are the current account, private credit, and a positive constant, respectively, and $\Delta$ represents the first difference in the variable.

Proof: See the online appendix.

Eq. (17) is directly estimable. Although Eq. (17) has a similar form to Eq. (22) in Kunieda and Shibata (2005), we note a key difference between them. In Eq. (22) in Kunieda and Shibata (2005), the first difference in land prices has a negative impact on the current account, whereas $\triangle P C_{t-1}$ has a negative impact on the current account in our newly derived solution (17). Additionally, the right-hand side of Eq. (17) incorporates the first 
difference in foreign reserves; this point is also absent in Eq. (22) in Kunieda and Shibata (2005).

Intuitively, the production resources are inefficiently allocated if the agents in the economy are collaterally constrained. More concretely, less land is allocated to borrowers and more to savers in our model compared to an economy with a perfect financial market. In the current model economy, if the collateral constraints are relaxed at time $t-1$ due to anticipation of an increase in land prices, constrained borrowers will increase their borrowing and their investment in land. Accordingly, production inefficiency is corrected, and the aggregate production in the entire economy will increase at time $t$. The increase in production leads to an increase in total savings for the entire economy, which positively affects the current account. The term $\beta \Delta Z_{t}$ in Eq. (17) reflects this effect.

The reallocation of land from unconstrained agents to constrained agents that is induced by the relaxation of the collateral constraints does not affect the consumption behavior of the unconstrained agents. There is no effect because their investment in the land market and savings in the credit market are perfect substitutes in their consumption smoothing. Therefore, the Euler equation, Eq. (3), is not subject to the land price. Without technological shocks to affect the agents' permanent income, the reallocation of land does not affect the consumption of unconstrained agents. In contrast, the consumption behavior of constrained agents is affected by land prices, as observed in Eq. (15). As land prices increase, each constrained agent's consumption increases as well. Due to credit constraints, investment in the land market and savings in the credit market are not perfect substitutes. It is better for constrained agents to increase borrowing and invest more in land because their marginal revenue involving an increase in land prices is greater than the market interest rate. Then, their consumption smoothing is subject to land prices even if no technological shocks occur that affect their permanent income. As a consequence, the aggregate consumption in the entire economy increases as land prices increase. This phenomenon is reflected in the last term of Eq. (17), which negatively affects the current account. 
Note that the increment in foreign reserves has a positive effect on the current account in Eq. (17). This effect results from agents' consumption and saving behavior, which in turn is affected by the government's behavior. In this sense, this positive effect on the current account represents an indirect impact because the direct increase in foreign reserves is already counted in the current account.

Constrained borrowers exist if and only if $\lambda>0$, and thus, the last term of Eq. (17) reflects collateral constraints. We statistically examine whether the coefficient of $\triangle P C_{t-1}$ is negative. ${ }^{11}$ The negative significant value of the coefficient of $\Delta P C_{t-1}$ implies that an economy faces a collateral constraint, and this collateral constraint impacts the current account. Our objective is to examine whether the current account is affected by domestic financial frictions, so it suffices to test whether the coefficient of $\triangle P C_{t-1}$ is negative, although we cannot directly identify the value of $\lambda$. One should note that when $\lambda$ is greater than zero, the effect of collateral constraints on the current account is magnified by country-specific variables $(\Psi)$ and $(\hat{x})$ given a discount factor $(\beta)$. For robustness checks, we also construct the $95 \%$ confidence intervals of the coefficient of $\Delta P C_{t-1}$ by applying semiparametric bootstrapping in addition to performing the standard $t$ test. $^{12}$

\section{Data}

We prepared an annual dataset of six Asian countries: Indonesia, Korea, Malaysia, the Philippines, Singapore, and Thailand. We assembled the data for each country for as long a period as possible until 2007. We did not include the data from 2008 onward to avoid the effect of the global financial crisis in 2008-2009 on the estimation. The initial year for each country is different due to data availability. To obtain data on the current account $(C A)$ and the net output $(Z)$, we assembled the gross national product (GNP), the gross domestic

\footnotetext{
${ }^{11}$ As in the Kiyotaki and Moore model, land is used as collateral in our model. One might argue that other assets could be used as collateral. For instance, asset-based lending to small firms associated with inventories is becoming popular in the United States. Nevertheless, land is still commonly used as collateral in many countries.

${ }^{12}$ One obvious feature of the Asian financial crisis is that the domestic interest rates spiked during the crisis. Although Eq. (17) does not capture the super short-run interest rate variation, it captures the effect of collateral constraints in the coefficient of $\Delta P C_{t-1}$.
} 
product (GDP), aggregate consumption, aggregate investment (which is defined as the sum of gross fixed capital formation and changes in inventories), and government spending from the database of International Financial Statistics, which was issued by the International Monetary Fund (IMF) on January 2011. All of these variables are deflated by the consumer price index.

The data on the current account $(C A)$ are computed as the GNP minus the sum of aggregate consumption, aggregate investment, and government spending. The net output $(Z)$ is computed as GDP minus aggregate investment and government spending. We use "total reserves minus gold" from the database of International Financial Statistics for the foreign reserves $(F R)$. The total reserves minus gold in the database are measured by the local currency, so following the procedure employed by Jeanne and Rancière (2011), we construct the real value of $F R$ by using the nominal exchange rate and the consumer price index. The data on private credit were collected from the database of the financial structure created by the World Bank (2012). In the database, we have a variable entitled "private credit by deposit money banks and other financial institutions to GDP," which is the private credit/GDP ratio. To obtain the data for real private credit, $P C$, we multiply the real GDP by the ratio. ${ }^{13}$

Although we used the ordinary least squares (OLS) method for the basic estimation for Eq. (17), we are concerned about an endogeneity problem associated with $\Delta Z_{t}$. For example, an increase in the demand for foreign investment may cause a decrease in domestic investment that increases $\Delta Z_{t}$, implying that a reverse causality from $C A_{t}$ to $\Delta Z_{t}$ could appear. Alternatively, there may be omitted variables such as the aging of the population that cannot be captured by Eq. (17) but that can certainly have an effect on the current account. As such, we also performed an instrumental variable (IV) estimation for Eq. (17) to check the robustness of the results from the OLS estimation. We used two-period lagged

\footnotetext{
${ }^{13}$ We tested the stationarity of each variable. Based on the results of the augmented Dickey-Fuller test and the Kwiatkowski-Phillips-Schmidt-Shin (1992) test and based on the intertemporal feasibility constraint of a country, we judge that all variables are stationary. The main results from the formal tests are provided upon request.
} 
aggregate investment and two-period lagged government spending as instrumental variables for $\Delta Z_{t}$. These variables were assembled from the aforementioned database of International Financial Statistics. In reality, production will take a certain gestation period and past investment should have a positive impact on current production without correlating with the current error term. Additionally, past government spending could be used to construct infrastructure that increases the productivity of the entire economy without correlating with the current error term. Considering realities, it is appropriate to use these variables as instrumental variables for the net output $\left(\Delta Z_{t}\right)$.

\section{Estimation Results}

\section{$\underline{\text { Benchmark Results }}$}

We estimated the current account dynamics given by Eq. (17). Following the convention, a constant term is always included in our estimation, although we do not report the estimated constant. The benchmark results on the six countries obtained from the OLS method are presented in Table 1.

[Table 1 around here]

Indonesia. The estimated coefficient of $\Delta P C_{t-1}$ is negative and significant at the conventional significance level for the one-sided test as predicted by our model. However, the $95 \%$ confidence interval of the coefficient includes zero. Therefore, we cannot robustly judge that collateral constraints affected the current account in the estimation period. The coefficients of $C A_{t-1}$ and $\Delta Z_{t}$ are positive as predicted by our model, but the impact of $\Delta Z_{t}$ is insignificant. The coefficient of $\Delta F R_{t}$ is positive as our model predicts, but it is insignificant.

Korea, Malaysia, and Singapore. These three countries obtain a similar result: although the coefficients of $C A_{t-1}$ and $\Delta Z_{t}$ are positive and significant, the coefficient of $\Delta P C_{t-1}$ is positive, as opposed to our model prediction, or negative but insignificant. The coefficients of $\Delta F R_{t}$ are positive, but they are insignificant in these countries.

The Philippines. The coefficients of $C A_{t-1}$ and $\Delta Z_{t}$ are positive and significant, and the 
coefficient of $\Delta P C_{t-1}$ is negative and significant. As in the case of Indonesia, however, the $95 \%$ confidence interval of the coefficient of $\Delta P C_{t-1}$ includes zero, and thus we cannot robustly judge that collateral constraints affected the current account during the estimation period. The coefficient of $\Delta F R_{t}$ is insignificant, although it is positive.

Thailand. As predicted by our model, the coefficients of $C A_{t-1}$ and $\Delta Z_{t}$ are positive and significant. The coefficient of $\Delta P C_{t-1}$ is negative but insignificant. The coefficient of $\Delta F R_{t}$ is negative and insignificant.

For any of these six countries, the benchmark results cannot confirm that collateral constraints matter to their current account dynamics throughout the estimation period. We must be careful, however, in several respects when we interpret these results. The error term of the estimation equation may be serially correlated as often occurs in time-series analyses. We then tested whether there is serial correlation in the error term by using the Ljung-Box $Q$ test (Ljung and Box, 1978). The $Q$ statistics of all six countries do not reject the null hypothesis of no serial correlation.

In addition, as discussed in section III, $\Delta Z_{t}$ may be an endogenous variable. We then conduct a robustness check by estimating Eq. (17) using the IV technique. The results are presented in Table 2, which shows that the patterns for the significance and signs of the coefficient of $\Delta P C_{t-1}$ for all countries except Indonesia are exactly the same as those in the OLS results in Table $1 .^{14}$ The coefficient of $\Delta P C_{t-1}$ in Indonesia in the IV estimation is insignificant, although it is negative. Moreover, the $95 \%$ confidence intervals of the coefficients of $\Delta P C_{t-1}$ for all six countries include zero. Finally, benchmark results are obtained from the entire sample estimations. However, these cannot uncover the structural change in the current account dynamics. As discussed in Bernanke's (2005) global saving glut hypothesis, it is highly likely that the pattern for the current account dynamics in Asian countries changed from before and to after the financial crisis in 1997-1998. Motivated by the global

\footnotetext{
${ }^{14}$ Although in Indonesia, Korea, and Malaysia, the patterns for the significance and signs of the coefficient of $\Delta Z_{t}$ are different from those in the OLS results, our interest is in the coefficient of $\Delta P C_{t-1}$.
} 
saving glut hypothesis, we performed the $F$-test in the next section to determine if there is a structural change in the current account dynamics.

[Table 2 around here]

\section{$\underline{\text { Structural Change }}$}

We examined whether there was a structural change in the impact of $\Delta P C_{t-1}$ before and after the 1997-1998 Asian financial crisis by applying the F-test. We searched for a structural change only in the coefficient of $\Delta P C_{t-1}$. We opened a test window from 1995 to 2000 . Figure 1 shows the $F$-values of the test for the structural change. As seen in the figure, the $F$-values for all six countries are greater than the $10 \%$ significance level for at least one year in the period 1997-2000. From the $F$-values in the figure, we judge that Korea, Singapore, and Thailand had structural changes in 1997 in the pattern of the current account dynamics, and Malaysia and the Philippines had structural changes in 1998. We judge that the structural change in Indonesia occurred in 2000 because the $F$-value in 2000 is greater than that in 1999.

[Figure 1 around here]

Table 3 presents the results obtained from the OLS estimations, dividing the data at each breaking point. The comparison between Tables 1 and 3 is remarkable.

[Table 3 around here]

Korea, Malaysia, the Philippines, and Thailand. Korea, Malaysia, the Philippines, and Thailand had an almost identical experience. Although Table 1 does not confirm that collateral constraints affected the current account dynamics in these countries throughout the estimation period, Table 3 indicates that before the financial crisis, collateral constraints did affect the current account dynamics in these four countries, with the current account being 
reduced by an increase in $\Delta P C_{t-1}$. The standard $t$ tests for these countries reject the null hypothesis that the coefficient of $\Delta P C_{t-1}$ is equal to zero and indicate that it is significantly negative. Moreover, for these four countries, the $95 \%$ confidence intervals of the coefficients of $\Delta P C_{t-1}$ do not include zero in the estimations before the financial crisis. ${ }^{15}$ We provide the bootstrap distributions of the coefficients of $\Delta P C_{t-1}$ for these four countries in Figure 2. We note from the figure that none of the distributions skew. The coefficients of $C A_{t-1}$ and $\Delta Z_{t}$ in these four countries are positive and significant before the financial crisis, as our model predicts. Only in Malaysia is the coefficient of $\Delta F R_{t}$ significantly positive.

[Figure 2 around here]

We have confirmed that in Korea, Malaysia, the Philippines, and Thailand, both $\Delta Z_{t}$ and $\triangle P C_{t-1}$ significantly affected the current account dynamics before the Asian financial crisis. In this case, which variable contributes more to the determination of the current account? It is interesting to investigate the relative importance of $\Delta Z_{t}$ (which reflects traditional consumption smoothing motives) and $\Delta P C_{t-1}$ (which reflects collateral constraints) for the determination of the current account. Huetter and Sunder (2012) propose decomposing the contributions of independent variables to $R$-squared, based on the Shapley value. ${ }^{16}$ The application of the method proposed by Huetter and Sunder yields the following results for each country. In Korea, the contribution of $\Delta Z_{t}$ to the $R$-squared in the pre-crisis estimation is $14.3 \%$ and that of $\Delta P C_{t-1}$ is $13.4 \%$. In Malaysia, the contribution of $\Delta Z_{t}$ is $13.9 \%$ and that of $\Delta P C_{t-1}$ is $22.5 \%$. In the Philippines, the contribution of $\Delta Z_{t}$ is $10.2 \%$ and that of $\Delta P C_{t-1}$ is $40.1 \%$. In Thailand, the contribution of $\Delta Z_{t}$ is $7.41 \%$ and that of $\Delta P C_{t-1}$ is $42.2 \%$. These outcomes convince us that collateral constraints played a crucial role in the current account dynamics before the financial crisis relative to traditional consumption

\footnotetext{
${ }^{15}$ Strictly speaking, the $95 \%$ confidence interval for Malaysia barely includes zero in the upper boundary of the interval.

${ }^{16}$ See Huetter and Sunder (2012) for the detailed procedures of the decomposition. Heineck and Süssmuth (2013) apply this decomposition to investigate the relative importance of independent variables to determine individual trust variation.
} 
smoothing motives.

Before the financial crisis, $\Delta P C_{t-1}$ has a significantly negative impact on the current account dynamics, but after the crisis, the impact of $\Delta P C_{t-1}$ becomes null. Although the post-crisis estimation results are untrustworthy because the sample size is too small, the important point of our estimation results is the discovery of structural changes in these four countries. Before the crisis, there were numerous capital inflows into Asian emerging economies. According to Bernanke's (2005) global saving glut hypothesis, these emerging economies did not always use these numerous funds in a productive fashion; poorly developed banking systems in these economies allocated these funds to less productive investment projects. Our empirical results obtained from estimations for Korea, Malaysia, the Philippines, and Thailand show that credit booms before the crisis were associated with collateral constraints. Credit booms ended when the crisis occurred and the investment demand in these countries decreased. Capital began to flow out of these countries, mostly to the United States, after the crisis. Bernanke's hypothesis notes that in response to the financial crisis, some governments in Asian countries, including those of Korea and Thailand, began to build up large quantities of foreign currency reserves, intervening in the financial markets. ${ }^{17}$ Furthermore, Bernanke suggests that the institutional weaknesses associated with developing countries' investment conditions, such as unsecured property rights, corruption, government ineffectiveness, and financial underdevelopment, could explain why capital outflows went directly to the United States. ${ }^{18}$ Based on Bernanke's global saving glut hypothesis, we can infer that massive capital outflow and the government's intervention in the financial market

\footnotetext{
${ }^{17}$ In particular, the IMF immediately got the monetary and fiscal policies of Indonesia, Korea, and Thailand under control after the financial crisis.

${ }^{18}$ Bernanke maintains that adequate financial and institutional development in Asian countries would reduce the current account surplus of these countries. Applying the panel regression approach employed by the pioneering work of Chinn and Prasad (2003), Chinn and Ito (2007) find evidence that is apparently consistent with the global saving glut hypothesis, indicating that a fully developed financial sector in a country can lead to a reduction in the current account balance provided that the country is endowed with a fully developed legal system and an open financial market. However, they conclude that few Asian countries are endowed with these types of legal systems and open markets, implying that most countries would actually experience higher savings with greater financial development. Gruber and Kamin (2007) demonstrate that the institutional-quality difference fails to explain the large current deficit of the United States. Therefore, this part of the global saving glut hypothesis remains an open empirical question.
} 
perturbed collateral-based lending in these countries, and thus, the impact of $\Delta P C_{t-1}$ on the current account dynamics becomes null after the crisis in our estimations.

Indonesia. The result for Indonesia is somewhat puzzling. Although the IMF controlled the monetary and fiscal policies in Indonesia immediately after the financial crisis, as mentioned in footnote 17, the standard $t$ test in Table 3 shows that the collateral constraints affected the current account dynamics from 2000 to 2007. This result contrasts with those for Korea, Malaysia, the Philippines, and Thailand. As discussed by Hill and Shiraishi (2007) and Ito (2007), Indonesia in 1997-1998 was involved not only in the financial crisis but also in a political crisis with respect to the end of the Soeharto regime. Our estimation result might reflect the political chaos at this time. Of course, this interpretation is tentative because there are only 8 observations after the financial crisis and the $95 \%$ confidence interval of the coefficient of $\Delta P C_{t-1}$ includes zero. In the period 1983-2000, the coefficient of $\Delta P C_{t-1}$ is not significant, although it is negative. This means that it is unlikely that collateral constraints in Indonesia affected the current account before the financial crisis. However, as seen in the robustness check using the closed-form solution for the current account derived from the stochastic model in the next section, the coefficient related to collateral constraints is significant in the same period. So, we have mixed evidence regarding whether collateral constraints in Indonesia affected the current account before the crisis.

Singapore. Although the $F$-value in Figure 1 indicates Singapore's structural change in 1997, the estimated coefficients of $\Delta P C_{t-1}$ in both the pre- and post-crisis estimations are positive, indicating that collateral constraints did not affect the current account throughout the estimation period. The $95 \%$ confidence intervals of the coefficients of $\triangle P C_{t-1}$ in both the pre- and post-crisis estimations include zero.

\section{$\underline{\text { Remark on Estimated Coefficients }}$}

Domestic collateral constraints significantly affect the current account before the Asian financial crisis in Korea, Malaysia, the Philippines, and Thailand, and Kiyotaki and Moore's (1997) model can be applied to these four countries before the crisis. Given these out- 
comes, it is worthwhile considering the implication of the other estimated coefficients on the underlying structural parameters.

The coefficient of $\Delta Z_{t}$ in the closed-form solution is $\beta$, which is the subjective discount factor. Many studies in the business cycles literature calibrate the subjective discount factor as 0.99 assuming that one period is a quarter. ${ }^{19}$ In our estimations, one period is a year, and thus $\beta=0.96$ is a plausible value in the business cycles literature. The estimated coefficients of $\Delta Z_{t}$ vary greatly from 0.029 (the period 1983-1999, Indonesia) to 1.078 (the period 1997-2007, Thailand). However, nine cases (the period 2000-2007, Indonesia; the period 1973-1996, Korea; the period 1997-2007, Korea; the period 1962-1997, Malaysia; the period 1998-2007, the Philippines; the period 1969-1996, Singapore; the period, 1997-2007, Singapore; the period 1968-1996, Thailand; the period 1997-2007, Thailand) out of twelve in Table 3 do not reject the null hypothesis that the coefficient of $\Delta Z_{t}$ is not different from 0.96 at the $10 \%$ significance level. The coefficient of $C A_{t-1}$ is $\beta R$, which is the subjective discount factor multiplied by the gross world interest rate. The estimated coefficients of $C A_{t-1}$ also vary greatly from 0.252 (the period 1983-1999, Indonesia) to 0.899 (the period 1962-1997, Malaysia). Assume that the net real world interest rate is $2 \%$, that is, $R=1.02$. If $\beta=0.96$, it follows that $\beta R=0.98$. Six cases in Table 3 (the period 2000-2007, Indonesia; the period 1973-1996, Korea; the period 1962-1997, Malaysia; the period 1969-1996, Singapore; the period 1997-2007, Singapore; the period 1997-2007, Thailand) do not reject the null hypothesis that the coefficient of $C A_{t-1}$ is not different from 0.98 at the $10 \%$ significance level. Lastly, the coefficient of $\Delta F R_{t}$ is $1-\beta$, which is computed as 0.04 . Eight cases (the period 1983-1999, Indonesia; the period 1973-1996, Korea; the period 1997-2007, Korea; the period 1962-1997, Malaysia; the period 1998-2007, Malaysia; the period 1962-1997, Philippines; the period 1969-1996, Singapore; the period 1997-2007, Singapore) do not reject the null hypothesis that the coefficient of $\Delta F R_{t}$ is not different from 0.04 at the $10 \%$ significance level.

\footnotetext{
${ }^{19}$ See, for instance, Hansen (1985) and Christiano et al. (2005), among others.
} 
We note that before the financial crisis in Korea and Malaysia, all of the estimated coefficients of $C A_{t-1}, \Delta Z_{t}$, and $\Delta F R_{t}$ in Table 3 are statistically harmonious with those plausible parameter values frequently used in the business cycles literature. Moreover, before the crisis in these two countries, collateral constraints played a crucial role in the determination of the current account as previously discussed. As such, our theoretical and empirical investigations demonstrate that there are real cases in which Kiyotaki and Moore's model with empirically plausible parameter values performs very well when determining the current account. ${ }^{20}$

\section{Extension to a Stochastic Model}

In this section, we extend the deterministic model in section II to a stochastic model and derive a closed-form solution for the current account. We focus on the stationary state in which all variables exhibit stationary distributions because the closed-form solution for the current account on the stochastic transitional path includes unobservables such as the expectations of future variables, and thus we cannot estimate the closed form. By assuming that an economy is in the stationary state, these unobservables become constant and their first differences are zero. Accordingly, we can derive a simple closed-form solution for the current account without unobservable variables. The derivation of the closed-form solution for the current account in the stochastic model is complicated, so the proof of Proposition 2 and the derivation of each equation are allocated to the online appendix. Although the model setting is the same as in section II, we depart from the basic model in that borrows' technology is subject to an aggregate shock in each period. Each borrower is endowed with a linear production technology such as $y_{t+1}=a_{t+1} x_{t}$, where $a_{t+1}$ is a random variable that is independent and identically distributed across time (the i.i.d. assumption). The support of $a_{t+1}$ is $[\underline{a}, \bar{a}]$ for all $t$. The mean of $a_{t+1}$ is $a$, namely, $E_{t}\left(a_{t+1}\right)=a$. All borrowers face the

\footnotetext{
${ }^{20}$ In the business cycles literature, although Cordoba and Ripoll (2004) show that Kiyotaki and Moore's (1997) model with empirically plausible parameter values leads to very weak amplification and propagation mechanisms, Mendicino (2012) shows that if we explicitly take into consideration inefficiencies in debt enforcement, we find strong amplification mechanisms even under empirically plausible values for preference and technology parameters.
} 
same productivity shock in each period. ${ }^{21}$

\section{$\underline{\text { Borrowers }}$}

The utility maximization problem of a borrower is almost the same as that of the basic model in section II except that $a_{t+1}$ and $q_{t+1}$ are random variables when she makes a decision about consumption and saving at time $t$. A borrower with a discount factor $\beta \in(0,1)$ solves the following maximization problem at time $t$ :

$$
\begin{aligned}
& \max E_{t}\left[\sum_{s=t}^{\infty} \beta^{s-t} \ln c_{s}\right] \\
\text { s.t. } & c_{s}+q_{s}\left(x_{s}-x_{s-1}\right)+R b_{s-1} \\
= & (1-\tau) a_{s} x_{s-1}+b_{s}, \\
& b_{s} \leq R^{-1} E_{s}\left(q_{s+1}\right) x_{s}
\end{aligned}
$$

for $s \geq t$. Differing from Eq. (9), the credit constraint is associated with $E_{s}\left(q_{s+1}\right)$. The Euler equation of a borrower is given by

$$
\frac{E_{t}\left(u_{t}\right)}{c_{t}}=\beta\left[(1-\tau) a+(1-\tau) \gamma_{t}^{2}+\gamma_{t}^{1}\right] E_{t}\left[\frac{1}{c_{t+1}}\right]
$$

where $\gamma_{t}^{1}=\operatorname{Cov}_{t}\left(q_{t+1}, 1 / c_{t+1}\right) / E_{t}\left(1 / c_{t+1}\right)$ and $\gamma_{t}^{2}=\operatorname{Cov}_{t}\left(a_{t+1}, 1 / c_{t+1}\right) / E_{t}\left(1 / c_{t+1}\right)$.

\section{Savers}

The utility maximization problem of a saver also follows that of the basic model in section II. A saver with a discount factor $\beta \in(0,1)$ solves the following maximization problem at

\footnotetext{
${ }^{21}$ The extension to a case in which savers also face productivity shocks is straightforward and obtains essentially the same closed form solution for the current account. To save notations and for simplicity, we discuss only the case in which borrowers face productivity shocks.
} 
time $t$ :

$$
\begin{aligned}
& \max E_{t}\left[\sum_{s=t}^{\infty} \beta^{s-t} \ln c_{s}^{*}\right] \\
\text { s.t. } & c_{s}^{*}+q_{s}\left(x_{s}^{*}-x_{s-1}^{*}\right)+I_{s}^{*}+R b_{s-1}^{*} \\
& =(1-\tau)\left[G_{1}\left(x_{s-1}^{*}\right)+G_{2}\left(k_{s-1}^{*}\right)\right]+b_{s}^{*},
\end{aligned}
$$

for $s \geq t$ where $I_{s}^{*}=k_{s}^{*}-(1-\delta) k_{s-1}^{*}$. The first-order conditions for a saver are given by the following:

$$
\begin{aligned}
& \frac{1}{c_{t}^{*}}=\beta R E_{t}\left[\frac{1}{c_{t+1}^{*}}\right] \\
& \frac{q_{t}}{c_{t}^{*}}=\beta\left[(1-\tau) G_{1}^{\prime}\left(x_{t}^{*}\right)+E_{t}\left(q_{t+1}\right)+\gamma_{t}\right] E_{t}\left[\frac{1}{c_{t+1}^{*}}\right] \\
& \frac{1}{c_{t}^{*}}=\beta\left[(1-\tau) G_{2}^{\prime}\left(k_{t}^{*}\right)+1-\delta\right] E_{t}\left[\frac{1}{c_{t+1}^{*}}\right],
\end{aligned}
$$

where $\gamma_{t}=\operatorname{Cov}_{t}\left(q_{t+1}, 1 / c_{t+1}^{*}\right) / E_{t}\left(1 / c_{t+1}^{*}\right)$.

Equilibrium

From Eqs. (19) and (21), the borrower's optimal consumption is obtained as follows:

$$
c_{t}=(1-\beta)\left[(1-\tau) a_{t} x_{t-1}+\left[q_{t}-E_{t-1}\left(q_{t}\right)\right] x_{t-1}\right] .
$$

Depending on the stochastic productivity shocks, $q_{t}-E_{t-1}\left(q_{t}\right)$ could be negative. In what follows, we assume that $\underline{a}$ is sufficiently large so that the right-hand side of Eq. (27) is 
positive. ${ }^{22}$ From Eqs. (23)-(26), the saver's optimal consumption is derived as follows:

$$
\begin{aligned}
& c_{t}^{*}=(1-\beta)\left[(1-\tau) y_{t}^{*}-I_{t}^{*}+q_{t} x_{t-1}^{*}-R b_{t-1}^{*}-\hat{x}^{*} q_{t}\right. \\
& \left.+\hat{x}^{*} E_{t}\left[\sum_{j=0}^{\infty} \gamma_{t+j} / R^{j+1}\right]+\left[(1-\tau) \hat{y}^{*}-\delta \hat{k}^{*}\right] /(R-1)+\tilde{\gamma}_{t}\right] .
\end{aligned}
$$

where $\tilde{\gamma}_{t}:=\lim _{s \rightarrow \infty} \operatorname{Cov}_{t}\left[\sum_{j=1}^{s} \tilde{\pi}_{t+j-1} / R^{j}, \frac{1}{c_{t+s}^{*}}\right] / E_{t}\left[1 / c_{t+s}^{*}\right]$ and $\tilde{\pi}_{t-1}=(1-\tau)\left(G_{1}\left(x_{t-1}^{*}\right)-\right.$ $\left.G_{1}^{\prime}\left(x_{t-1}^{*}\right) x_{t-1}^{*}\right)+(1-\tau)\left(G_{2}\left(k_{t-1}^{*}\right)-G_{2}^{\prime}\left(k_{t-1}^{*}\right)\right) k_{t-1}^{*}$. From Eqs. (27) and (28), we can derive a simple closed-form solution for the current account in the stationary state in which all variables exhibit stationary distributions with the i.i.d. assumption for $a_{t}$ because $\gamma_{t}$ and $\tilde{\gamma}_{t}$ are constant in the stationary state.

\section{Proposition 2}

The closed-form solution for the current account in the stationary state of the stochastic economy is given as follows:

$$
C A_{t}=\beta R C A_{t-1}+(1-\beta) \Delta F R_{t}+\beta \Delta Z_{t}-(1-\beta) \Omega \lambda \hat{x} \Delta P C_{t},
$$

where $\Omega$ is a positive constant.

Proof: See the online appendix.

The difference between Eq. (17) and Eq. (29) is that although $\Delta P C_{t-1}$ is associated with $C A_{t}$ in Eq. (17), $\triangle P C_{t}$ is associated with $C A_{t}$ in Eq. (29). Eq. (17), derived from the deterministic model, is applied when an economy is on a deterministic transitional path to the steady-state equilibrium. In this case, the increase in $q_{t}$ relaxes the collateral constraint at time $t-1$ and directly induces an increase in $b_{t-1}$ and thus $P C_{t-1}$ (see Eq.

\footnotetext{
${ }^{22}$ We do not consider borrowers' defaults. Our objective is to examine the performance of Kiyotaki and Moore's (1997) model and test whether borrowers in real economies face collateral constraints using macroeconomic data, without specifying any hypothetical distribution regarding productivity shocks. As seen in Eq. (27), to consider borrowers' defaults, it is necessary to numerically derive a stationary distribution of the land price from a hypothetical distribution of productivity shocks. This calibration procedure is beyond the scope of this paper. The reader who is interested in studies on recent sovereign defaults in emerging economies is referred to Arellano (2008).
} 
(9)). Then, as discussed in section II, each constrained borrower invests more in land at time $t-1$ and consumes more at time $t$. Because unconstrained savers do not change their consumption and saving plan, aggregate consumption at time $t$ increases, and thus we can derive the negative relationship between $C A_{t}$ and $\Delta P C_{t-1}$ in the deterministic model. By contrast, the mechanism through which the negative relationship between $C A_{t}$ and $\triangle P C_{t}$ occurs in the stationary state of the stochastic model is completely different. Consider a case in which borrowers experience a high productivity shock at time $t$. In this case, each constrained borrower's demand for land $\left(x_{t}\right)$ increases, and thus the land price at time $t\left(q_{t}\right)$ increases. Because the credit constraint (20) is relaxed by an increase in $x_{t}, b_{t}$ and thus $P C_{t}$ increase even though $E_{t}\left(q_{t+1}\right)$ in the credit constraint is constant in the stationary state. Accordingly, we can observe the positive relationship between $\Delta q_{t}$ and $\Delta P C_{t}$. From Eq. (21) with $u_{t}=q_{t}-q_{t+1} / R$, it is noted that an increase in $q_{t}$ induces more consumption from borrowers at time $t$ in the stationary state. As such, aggregate consumption at time $t$ increases because of an increase in $q_{t}$, and thus, we can derive the negative relationship between $C A_{t}$ and $\triangle P C_{t}$ in the stationary state of the stochastic model.

$\underline{\text { Robustness checks }}$

In reality, we do not know whether an economy is on the deterministic transitional path as investigated in section II, on the stochastic transitional path (for which we cannot estimate the closed-form solution because of the unobservable variables), or in the stochastic stationary state as investigated in this section. For robustness checks, therefore, we estimate Eq. (29) and produce estimation results comparable to those in Table 3. As seen in Table 4, the results regarding collateral constraints (namely, the coefficients of $\triangle P C_{t}$ ) are similar to those in Table 3 with some exceptions. Although the coefficient of $\triangle P C_{t}$ in Korea for the period 1997-2007 is significant in contrast with that in Table 3, the post-crisis estimation results are untrustworthy because of the small sample size. Moreover, the $95 \%$ confidence interval of the coefficient definitely includes zero. Therefore, the result in Table 4 for the effect of collateral constraints on the current account in Korea is tentative for the period 1997-2007. 
We judge that after the financial crisis, the impact of $\Delta P C_{t}$ on the current account becomes null in Korea. Regarding Indonesia, the estimation result in the period 1983-1999 in Table 4 differs from that in Table 3. The coefficient of $\triangle P C_{t}$ in Table 4 is significant for the period 1983-1999, and the $95 \%$ confidence interval of the coefficient does not include zero for the same period. Judging from the results in Tables 3 and 4, there is mixed evidence regarding the impact of collateral constraints on the current account before the crisis in Indonesia.

[Table 4 around here]

\section{DISCUSSION}

The current paper relates to the literature on the intertemporal current account (ICA) approach. The ICA approach has been the dominant theoretical framework for investigating the determinants of the current account dynamics over the last three decades. Early influential papers such as Sachs (1981), Obstfeld (1982), and Johnson (1986) led to wide use of the ICA approach to study the current account dynamics. According to the ICA approach, current account imbalances are an outcome of optimal intertemporal saving and investment decisions (Obstfeld and Rogoff, 1995). Most empirical studies in this literature use Campbell and Shiller's (1987) methodology to derive a directly estimable closed-form solution for the current account dynamics. Typical empirical studies along this line include Sheffrin and Woo (1990), Milbourne and Otto (1992), Otto (1992), and Ghosh (1995). Generally speaking, the empirical fits for these simple ICA models are relatively poor, and subsequent authors have improved the models in various directions. Some endogenize investment dynamics, separating them from output dynamics, and others incorporate time-varying interest rates. In these studies, many researchers focus on the effects from global and country-specific shocks and/or permanent and temporary shocks on the current account. As demonstrated by Glick and Rogoff (1995) and Razin (1995), a global shock does not impact the current account because agents in a small open economy are uninsured against a global shock and their con- 
sumption cannot be optimally smoothed. However, a country-specific shock does affect the current account because agents mitigate the effects of the shock by adjusting their optimal consumption and saving behavior through the international financial markets. By deriving a closed-form current account solution, Kano (2008) examines the response of the current account to three different shocks - global, country-specific permanent, and country-specific transitory shocks - and discovers that consumption-tilting factors are crucial for explaining the current account movements in Canada and the United Kingdom. ${ }^{23}$

Moreover, applying Campbell and Mankiw's (1989) methodology, Shibata and Shintani (1998) and Bussière et al. (2010) introduce into the ICA model agents who cannot access international financial markets. Considering country-specific shocks to net output, Shibata and Shintani (1998) derive an explicit solution for the current account dynamics and estimate the dynamics for 11 countries of the Organisation for Economic Co-operation and Development (OECD). They find evidence showing the existence of international financial market imperfections for Canada, France, Japan, the United Kingdom, and the United States among the 11 countries. Bussière et al. (2010) obtain an estimable current account equation in the presence of global, productivity, and budget deficit shocks. Estimating the equation, they investigate the response of the current account to these shocks for the 21 OECD member countries.

Although the empirical literature on the ICA approach has investigated the effects from various shocks on the current account, few researchers have explicitly focused on the effects of domestic financial frictions. Kasa (1998) and Kunieda and Shibata (2005) are notable exceptions. ${ }^{24}$ Kasa extends Kiyotaki and Moore's (1997) model to a small open economy and derives closed-form solutions to the land price and the current account dynamics. Estimating these dynamics for Japan, Korea, and Hong Kong, Kasa finds that the degree of credit

\footnotetext{
${ }^{23}$ See Ghosh (1995), Kano (2008), and Braeu (2010) for details on consumption-tilting factors.

${ }^{24}$ Recently, some researchers such as Adam et al. (2012), Punzi (2013), and Ferrero (2015) study current account imbalances in an economy with financial frictions that are associated with housing markets. Differing from the traditional ICA approach, they use calibration to measure the impacts of financial frictions on the current account.
} 
constraint is quite severe in these countries. Based on Kasa's model, Kunieda and Shibata develop a small open economy version of Kiyotaki and Moore's (1997) model to derive a closed-form current account solution in a collaterally constrained economy. Their closedform solution is associated with the first difference in land prices: if land prices increase from time $t-1$ to $t$, the current account decreases at time $t$ because of the relaxation of the collateral constraints. Using data on the Japanese economy, the authors estimate the current account dynamics in the Japanese economy and conclude that the Japanese economy was collaterally constrained from 1959 to 2001.

Kunieda and Shibata's (2005) closed-form current account solution is so simple that we can directly estimate the current account dynamics. However, we must prepare the land price data for the estimation, and there are relatively few countries for which we can collect land price data over a long period. Additionally, the quality of land price data is often poor: if we try to assemble the data, we would likely be driven to using a "house price index" as a proxy for the land price in many countries. In contrast to Kunieda and Shibata (2005), we derived two new closed-form solutions for the current account: one is associated with the one-period-lagged first difference in private credit in the deterministic model and the other is associated with the current-period first difference in private credit in the stochastic model. The private credit data are available in most countries over a long period and are reliable. Therefore, the newly derived closed-form current account solution associated with private credit benefits us.

\section{Concluding Remarks}

We applied a small open economy version of Kiyotaki and Moore's (1997) model to derive a closed-form solution for the current account dynamics. By using the closed-form solution, we examined the performance of Kiyotaki and Moore's (1997) model and investigated how collateral constraints impact the current account dynamics in Asian countries before and after the Asian financial crisis in 1997-1998. If the coefficient of $\Delta P C_{t-1}$ in Eq. (17) is significantly negative, the Kiyotaki and Moore model is statistically accepted for a country, 
and we consider domestic financial frictions to affect the current account dynamics in the country. The entire sample analysis cannot uncover the structural change in the coefficient of the one-period-lagged first difference in private credit, which is an indicator of the impact of collateral constraints. Therefore, we conducted an $F$-test for the structural change and estimated the current account dynamics, dividing the data at the breaking point of the structural change. Korea, Malaysia, the Philippines, and Thailand have an almost identical experience with respect to the current account dynamics before and after the financial crisis: our estimations demonstrated that collateral constraints significantly affected the current account dynamics before the financial crisis in these four countries but that after the crisis, collateral constraints had no effect on the current account. We, furthermore, derived a closedform solution for the current account from the stochastic model and estimated the equation. We obtain similar results to those from the estimation of the deterministic model. Our study provides researchers and policymakers with a new perspective with regard to financial crises in the era of globalization in that it clarifies how the impact of domestic financial frictions on the current account dynamics changes before and after a financial crisis.

In this paper, we have focused on estimations of the current account dynamics. However, there is another dynamic equation that can be directly estimated in our model: Eq. (A3) in the online appendix. Eq. (A3) is a closed-form solution for the consumption dynamics. In particular, the second term of the right-hand side represents the wealth effect of land holdings, and this term can be rewritten in terms of the one-period-lagged first difference in private credit. We can investigate the consumption dynamics in economies with financial frictions but leave this empirical question for future research.

\section{References}

[1] Adam, K., P. Kuang, and A. Marcet. "House Price Booms and the Current Account," in NBER Macroeconomics Annual 2011, edited by D. Acemoglu and M. Woodford. 
Chicago: University of Chicago Press, 2012, 77-122.

[2] Aghion, P., P. Howitt, and D. Mayer-Foulkes. "The Effect of Financial Development on Convergence: Theory and Evidence." Quarterly Journal of Economics, 120(1), 2005, $173-222$.

[3] Arellano, C. "Default Risk and Income Fluctuations in Emerging Economies." American Economic Review, 98(3), 2008, 690-712.

[4] Berger, A. N., and G. F. Udell. "Small Business Credit Availability and Relationship Lending: The Importance of Bank Organisational Structure." Economic Journal, 112(477), 2002, F32-F53.

[5] Bernanke, B. S. "The Global Saving Glut and the U.S. Current Account Deficit." 2005, http://www.federalreserve.gov/boarddocs/speeches/2005/200503102/

[6] Bernanke, B., and M. Gertler. "Agency Costs, Net Worth, and Business Fluctuations." American Economic Review, 79(1), 1989, 14-31.

[7] Braeu, R. "Consumption Tilting and the Current Account: Evidence from Canada." International Review of Economics and Finance, 19(2), 2010, 304-12.

[8] Bussière, M., M. Fratzscher, and G. J. Müller. "Productivity Shocks, Budget Deficits and the Current Account." Journal of International Money and Finance, 29(8), 2010, 1562-79.

[9] Campbell, J. Y., and N. G. Mankiw. "Consumption, Income, and Interest Rates: Reinterpreting the Time Series Evidence," in NBER Macroeconomics Annual 1989, edited by O. J. Blanchard and S. Fischer. Cambridge: MIT Press, 1989, 185-216.

[10] Campbell, J. Y., and R. J. Shiller. "Cointegration and Tests of Present Value Models." Journal of Political Economy, 95(5), 1987, 1062-88. 
[11] Charumilind, C., R. Kali, and Y. Wiwattanakantang. "Connected Lending: Thailand Before the Financial Crisis." Journal of Business, 79(1), 2006, 181-218.

[12] Chinn, M. D., and H. Ito. "Current Account Balances, Financial Development and Institutions: Assaying the World "Saving Glut."" Journal of International Money and Finance, 26(4), 2007, 546-69.

[13] Chinn, M. D., and E. S. Prasad. "Medium-term Determinants of Current Accounts in Industrial and Developing Countries: An Empirical Exploration." Journal of International Economics, 59(1), 2003, 47-76.

[14] Christiano, L. J., M. Eichenbaum, and C. L. Evans. "Nominal Rigidities and the Dynamic Effects of a Shock to Monetary Policy." Journal of Political Economy, 113(1), $2005,1-45$.

[15] Cordoba, J.-C., and M. Ripoll. "Credit Cycles Redux." International Economic Review, 45(4), 2004, 1011-46.

[16] Corsetti, G., P. Pesenti, and N. Roubini. "What Caused the Asian Currency and Financial Crisis?" Japan and the World Economy, 11(3), 1999, 305-73.

[17] Driffield, N., and S. Pal. "The East Asian Crisis and Financing Corporate Investment: Is There a Cause for Concern?" Journal of Asian Economics, 12(4), 2001, 507-27.

[18] Ferrero, A. "House Price Booms, Current Account Deficits, and Low Interest Rates." Journal of Money, Credit and Banking, 47(S1), 2015, 261-93.

[19] Finlay, K., and L. M. Magnusson. "Implementing Weak-instrument Robust Tests for a General Class of Instrumental-variables Models." Stata Journal, 9(3), 2009, 398-421.

[20] Galor, O., and J. Zeira. "Income Distribution and Macroeconomics." Review of Economic Studies, 60(1), 1993, 35-52. 
[21] Ghosh, A. R. "International Capital Mobility amongst the Major Industrialised Countries: Too Little or Too Much?" Economic Journal, 105(428), 1995, 107-28.

[22] Glick, R., and K. Rogoff. "Global versus Country-specific Productivity Shocks and the Current Account." Journal of Monetary Economics, 35(1), 1995, 159-92.

[23] Gruber, J. W., and S. B. Kamin. "Explaining the Global Pattern of Current Account Imbalances." Journal of International Money and Finance, 26(4), 2007, 500-22.

[24] Hansen, G. D. "Indivisible Labor and the Business Cycle." Journal of Monetary Economics, 16(3), 1985, 309-27.

[25] Heineck, G., and B. Süssmuth. "A Different Look at Lenin's Legacy: Social Capital and Risk Taking in the Two Germanies." Journal of Comparative Economics, 41(3), 2013, 789-803.

[26] Hill, H., and T. Shiraishi. "Indonesia After the Asian Crisis." Asian Economic Policy Review, 2(1), 2007, 123-41.

[27] Huettner, F., and M. Sunder. "Axiomatic Arguments for Decomposing Goodness of Fit According to Shapley and Owen Values." Electronic Journal of Statistics, 6, 2012, 1239-50.

[28] International Monetary Fund. International Financial Statistics. Washington, DC: International Monetary Fund, 2011.

[29] Ito, T. "Asian Currency Crisis and the International Monetary Fund, 10 Years Later: Overview." Asian Economic Policy Review, 2(1), 2007, 16-49.

[30] Jeanne, O., and R. Rancière. "The Optimal Level of International Reserves for Emerging Market Countries: A New Formula and Some Applications." Economic Journal, 121(555), 2011, 905-30. 
[31] Johnson, D. "Consumption, Permanent Income, and Financial Wealth in Canada: Empirical Evidence on the Intertemporal Approach to the Current Account." Canadian Journal of Economics, 19(2), 1986, 189-206.

[32] Kano, T., "A Structural VAR Approach to the Intertemporal Model of the Current Account." Journal of International Money and Finance, 27(5), 2008, 757-79.

[33] Kasa, K., "Borrowing Constraints and Asset Market Dynamics: Evidence from the Pacific Basin." Federal Reserve Bank of San Francisco Economic Review, 3, 1998, 1728.

[34] Kikuchi, T. "International Asset Market, Nonconvergence, and Endogenous Fluctuations." Journal of Economic Theory, 139(1), 2008, 310-34.

[35] Kikuchi, T., and J. Stachurski. "Endogenous Inequality and Fluctuations in a TwoCountry Model." Journal of Economic Theory, 144(4), 2009, 1560-71.

[36] Kiyotaki, N., and J. Moore. "Credit Cycles." Journal of Political Economy, 105(2), 1997, 211-48.

[37] Kunieda, T., and A. Shibata. "Credit Constraints and the Current Account: A Test for the Japanese Economy." Journal of International Money and Finance, 24(8), 2005, 1261-77.

[38] Kunieda, T., and A. Shibata. "Endogenous Growth and Fluctuations in an Overlapping Generations Economy with Credit Market Imperfections." Asia-Pacific Journal of Accounting \&5 Economics, 18(3), 2011, 333-57.

[39] Kunieda, T., and A. Shibata. "Credit Market Imperfections and Macroeconomic Instability." Pacific Economic Review, 19(5), 2014, 592-611.

[40] Kwiatkowski, D., P. C. B. Phillips, P. Schmidt, and Y. Shin. "Testing the Null Hypothesis of Stationarity against the Alternative of a Unit Root: How Sure Are We that 
Economic Time Series Have a Unit Root?" Journal of Econometrics, 54(1-3), 1992, 159-78.

[41] Ljung, G. M., and G. E. P. Box. "On a Measure of Lack of Fit in Time Series Models." Biometrika, 65(2), 1978, 297-303.

[42] Matsuyama, K. "Credit Traps and Credit Cycles." American Economic Review, 97(1), $2007,503-16$.

[43] Matsuyama, K. "The Good, the Bad, and the Ugly: An Inquiry into the Causes and Nature of Credit Cycles." Theoretical Economics, 8(3), 2013, 623-51.

[44] Mendicino, C. "On the Amplification Role of Collateral Constraints." Economics Letters 117(2), 2012, 429-35.

[45] Menkhoff, L., D. Neuberger, and C. Suwanaporn. "Collateral-based Lending in Emerging Markets: Evidence from Thailand." Journal of Banking EG Finance, 30(1), 2006, $1-21$.

[46] Milbourne, R., and G. Otto. "Consumption Smoothing and the Current Account." Australian Economic Papers, 31(59), 1992, 369-84.

[47] Myerson, R. B. "A Model of Moral-Hazard Credit Cycles." Journal of Political Economy, 120(5), 2012, 847-78.

[48] Obstfeld, M. "Aggregate Spending and the Terms of Trade: Is There a Laursen-Metzler Effect?" Quarterly Journal of Economics, 97(2), 1982, 251-70.

[49] Obstfeld, M., and K. Rogoff. "The Intertemporal Approach to the Current Account," in Handbook of International Economics Vol. 3, edited by G. M. Grossman and K. Rogoff. Amsterdam: Elsevier, 1985, 1731-99. 
[50] Otto, G. "Testing a Present-value Model of the Current Account: Evidence from US and Canadian Time Series." Journal of International Money and Finance, 11(5), 1992, 414-30.

[51] Pintus, P. A., and Y. Wen. "Leveraged Borrowing and Boom-Bust Cycles." Review of Economic Dynamics, 16(4), 2013, 617-33.

[52] Punzi, M. T. "Housing Market and Current Account Imbalances in the International Economy." Review of International Economics, 21(4), 2013, 601-13.

[53] Razin, A. "The Dynamic-optimizing Approach to the Current Account: Theory and Evidence," in Understanding Interdependence: The Macroeconomics of the Open Economy, edited by P. B. Kenen. Princeton: Princeton University Press, 1995, 169-98.

[54] Sachs, J. D. "The Current Account and Macroeconomic Adjustment in the 1970s." Brookings Papers on Economic Activity, 12(1), 1981, 201-68.

[55] Sheffrin, S. M., and W. T. Woo. "Present Value Tests of an Intertemporal Model of the Current Account." Journal of International Economics, 29(3-4), 1990, 237-53.

[56] Shibata, A., and M. Shintani. "Capital Mobility in the World Economy: An Alternative Test." Journal of International Money and Finance, 17(5), 1998, 741-56.

[57] Woo, W. T., J. D. Sachs, and K. Schwab, ed. The Asian Financial Crisis: Lessons for a Resilient Asia. Cambridge: MIT Press, 2000.

[58] World Bank. Global Financial Development Database. Washington, DC: World Bank, 2012. 
TABLE 1

OLS Estimation

\begin{tabular}{llllllll}
\hline \multirow{2}{*}{ Country } & Period & $C A_{t-1}$ & $\Delta F R_{t}$ & $\Delta Z_{t}$ & $\Delta P C_{t-1}$ & $\left(\Delta P C_{t-1}\right)$ & $\mathrm{R}^{2}$ \\
\hline Indonesia & $1983-2007$ & $0.408^{* *}$ & 0.010 & 0.241 & $-0.161^{* *}$ & {$[-0.491,0.168]$} & 0.41 \\
& & $(0.230)$ & $(0.027)$ & $(0.244)$ & $(0.091)$ & & \\
Korea & \multirow{2}{*}{$1973-2007$} & $0.500^{* * *}$ & 0.060 & $0.644^{* *}$ & -0.097 & {$[-0.550,0.355]$} & 0.66 \\
& & $(0.115)$ & $(0.047)$ & $(0.304)$ & $(0.219)$ & & \\
Malaysia & \multirow{2}{*}{$1962-2007$} & $0.854^{* * *}$ & 0.023 & $0.897^{* * *}$ & 0.056 & {$[-0.172,0.284]$} & 0.95 \\
& & $(0.065)$ & $(0.125)$ & $(0.251)$ & $(0.109)$ & & \\
Philippines & \multirow{2}{*}{$1962-2007$} & $0.913^{* * *}$ & 0.010 & $0.698^{* * *}$ & $-0.098^{*}$ & {$[-0.243,0.047]$} & 0.97 \\
& & $(0.029)$ & $(0.008)$ & $(0.107)$ & $(0.065)$ & & \\
Singapore & \multirow{2}{*}{$1969-2007$} & $0.863^{* * *}$ & 0.003 & $1.041^{* * *}$ & 0.198 & {$[-0.037,0.433]$} & 0.98 \\
& & $(0.064)$ & $(0.158)$ & $(0.100)$ & $(0.094)$ & & \\
Thailand & $1968-2007$ & $0.923^{* * *}$ & -0.045 & $1.125^{* * *}$ & -0.055 & {$[-0.207,0.096]$} & 0.87 \\
& & $(0.159)$ & $(0.029)$ & $(0.229)$ & $(0.059)$ & & \\
\hline
\end{tabular}

Notes: The dependent variable is the current account, $C A_{t}$. All estimations include constant terms, although we do not report the estimated constants here. The asterisks $* * *, * *$, and * indicate the 1\%, 5\%, and $10 \%$ significance levels, respectively, for the one-sided tests. The numbers in parentheses are the heteroskedasticity-robust standard errors. The $95 \%$ confidence interval (CI) of the coefficient of $\Delta P C_{t-1}$ is computed based on 10,000 bootstrapping repetitions. 
TABLE 2

IV Estimation

\begin{tabular}{llllllllll}
\hline Country & Period & $C A_{t-1}$ & $\Delta F R_{t}$ & $\Delta Z_{t}$ & $\Delta P C_{t-1}$ & $\begin{array}{l}95 \% \mathrm{CI} \\
\left(\Delta P C_{t-1}\right)\end{array}$ & $\begin{array}{l}\text { First-stage } \\
\text { F-value }\end{array}$ & $\begin{array}{l}\text { Hansen test } \\
(p \text {-value })\end{array}$ & $\begin{array}{l}\text { LM test } \\
(p \text {-value })\end{array}$ \\
\hline Indonesia & $1983-2007$ & 0.258 & 0.043 & -0.173 & -0.143 & {$[-0.749,0.463]$} & 4.99 & 0.64 & 0.34 \\
& & $(0.261)$ & $(0.039)$ & $(0.246)$ & $(0.118)$ & & & & \\
Korea & \multirow{2}{*}{$1973-2007$} & $0.488^{* * *}$ & $0.061^{*}$ & 0.593 & -0.079 & {$[-1.031,0.872]$} & 5.18 & 0.77 & 0.14 \\
& & $(0.103)$ & $(0.044)$ & $(0.581)$ & $(0.249)$ & & & & \\
Malaysia & $1962-2007$ & $1.008^{* * *}$ & 0.167 & 0.007 & 0.276 & {$[-0.871,1.422]$} & 3.27 & 0.92 & 0.97 \\
& & $(0.093)$ & $(0.139)$ & $(0.434)$ & $(0.253)$ & & & & \\
Philippines & \multirow{2}{*}{$1962-2007$} & $0.892^{* * *}$ & 0.008 & $0.786^{* * *}$ & $-0.109^{* *}$ & {$[-0.286,0.068]$} & 10.72 & 0.50 & 0.00 \\
& & $(0.028)$ & $(0.007)$ & $(0.094)$ & $(0.063)$ & & & & \\
Singapore & $1969-2007$ & $0.849^{* * *}$ & -0.011 & $1.109^{* * *}$ & 0.210 & {$[-0.109,0.530]$} & 15.54 & 0.43 & 0.00 \\
& & $(0.067)$ & $(0.159)$ & $(0.238)$ & $(0.099)$ & & & & \\
Thailand & $1968-2007$ & $0.916^{* * *}$ & -0.044 & $1.076^{* * *}$ & -0.054 & {$[-0.339,0.231]$} & 10.21 & 0.07 & 0.13 \\
& & $(0.153)$ & $(0.030)$ & $(0.298)$ & $(0.056)$ & & & & \\
\hline
\end{tabular}

Notes: The dependent variable is the current account, $C A_{t}$. All estimations include constant terms, although we do not report the estimated ones. The asterisks $* * *, * *$, and * indicate the $1 \%, 5 \%$, and $10 \%$ significance levels, respectively, for the one-sided tests. The numbers in parentheses are the heteroskedasticity-robust standard errors. The $95 \%$ confidence interval (CI) of the coefficient of $\Delta P C_{t-1}$ is computed based on 10,000 bootstrapping repetitions. The instrumental variables for $\Delta Z_{t}$ are the two-period-lagged aggregate investment and the two-period-lagged government expenditure. The Hansen tests of overidentifyng restrictions do not reject the orthogonality conditions in all estimations. The LM tests are robust to weak instruments and the $p$-values are associated with the significance of the coefficient of $\Delta Z_{t}$. See Finlay and Magnusson (2009) for more information on the LM test. 
TABLE 3

OLS Estimation Before and After the Financial Crisis

\begin{tabular}{|c|c|c|c|c|c|c|c|}
\hline Country & Period & $C A_{t-1}$ & $\Delta F R_{t}$ & $\Delta Z_{t}$ & $\Delta P C_{t-1}$ & $\begin{array}{l}95 \% \mathrm{CI} \\
\left(\Delta P C_{t-1}\right)\end{array}$ & $\mathrm{R}^{2}$ \\
\hline \multirow[t]{4}{*}{ Indonesia } & 1983-1999 & 0.252 & 0.059 & 0.029 & -0.228 & {$[-0.788,0.331]$} & 0.19 \\
\hline & & $(0.368)$ & $(0.077)$ & $(0.427)$ & $(0.207)$ & & \\
\hline & $2000-2007$ & $0.522 * *$ & -0.053 & $0.559^{*}$ & $-0.350 * *$ & {$[-2.114,1.414]$} & 0.86 \\
\hline & & $(0.205)$ & $(0.027)$ & $(0.253)$ & $(0.107)$ & & \\
\hline \multirow[t]{4}{*}{ Korea } & 1973-1996 & $0.814^{* * *}$ & 0.038 & $0.706^{* * *}$ & $-0.636^{* * *}$ & {$[-0.893,-0.378]$} & 0.83 \\
\hline & & $(0.121)$ & $(0.053)$ & $(0.189)$ & $(0.097)$ & & \\
\hline & $1997-2007$ & 0.333 & 0.041 & 0.650 & 0.025 & {$[-13.864,13.915]$} & 0.29 \\
\hline & & $(0.234)$ & $(0.064)$ & $(0.693)$ & $(0.363)$ & & \\
\hline \multirow[t]{4}{*}{ Malaysia } & $1962-1997$ & $0.899 * * *$ & $0.101^{*}$ & $0.704^{* * *}$ & $-0.129 * * *$ & {$[-0.259,0.000]$} & 0.81 \\
\hline & & $(0.121)$ & $(0.063)$ & $(0.165)$ & $(0.028)$ & & \\
\hline & $1998-2007$ & $0.792^{* * *}$ & 0.009 & $0.481^{* *}$ & 0.463 & {$[-4.642,5.568]$} & 0.95 \\
\hline & & $(0.088)$ & $(0.109)$ & $(0.213)$ & $(0.168)$ & & \\
\hline \multirow[t]{4}{*}{ Philippines } & $1962-1997$ & $0.630 * * *$ & 0.018 & $0.444^{* *}$ & $-0.243^{* *}$ & {$[-0.486,-0.001]$} & 0.71 \\
\hline & & $(0.202)$ & $(0.017)$ & $(0.207)$ & $(0.104)$ & & \\
\hline & $1998-2007$ & $0.876^{* * *}$ & -0.003 & $0.869^{* * *}$ & -0.012 & {$[-34.930,34.905]$} & 1.00 \\
\hline & & $(0.024)$ & $(0.005)$ & $(0.176)$ & $(0.020)$ & & \\
\hline \multirow[t]{4}{*}{ Singapore } & 1969-1996 & $0.763^{* * *}$ & -0.056 & $0.936^{* * *}$ & 0.273 & {$[-0.017,0.562]$} & 0.97 \\
\hline & & $(0.128)$ & $(0.264)$ & $(0.116)$ & $(0.121)$ & & \\
\hline & $1997-2007$ & $0.875^{* * *}$ & 0.171 & $1.043^{* * *}$ & 0.354 & {$[-10.428,11.135]$} & 0.95 \\
\hline & & $(0.128)$ & $(0.272)$ & $(0.147)$ & $(0.210)$ & & \\
\hline \multirow[t]{4}{*}{ Thailand } & 1968-1996 & $0.689^{* * *}$ & -0.040 & $0.713^{* * *}$ & $-0.176 * * *$ & {$[-0.279,-0.072]$} & 0.94 \\
\hline & & $(0.101)$ & $(0.019)$ & $(0.169)$ & $(0.033)$ & & \\
\hline & $1997-2007$ & $0.866^{* *}$ & -0.037 & $1.078^{* *}$ & 0.004 & {$[-1.017,1.026]$} & 0.68 \\
\hline & & $(0.333)$ & $(0.035)$ & $(0.400)$ & $(0.089)$ & & \\
\hline
\end{tabular}

Notes: The dependent variable is the current account, $C A_{t}$. All estimations include constant terms, although we do not report the estimated constants here. The asterisks ***, **, and * indicate the 1\%, 5\%, and $10 \%$ significance levels, respectively, for the one-sided tests. The numbers in parentheses are the heteroskedasticity-robust standard errors. The $95 \%$ confidence interval (CI) of the coefficient of $\Delta P C_{t-1}$ is computed based on 10,000 bootstrapping repetitions. 
TABLE 4

OLS Estimation Before and After the Financial Crisis (Robustness)

\begin{tabular}{|c|c|c|c|c|c|c|c|}
\hline Country & Period & $C A_{t-1}$ & $\Delta F R_{t}$ & $\Delta Z_{t}$ & $\Delta P C_{t}$ & $\begin{array}{l}95 \% \mathrm{CI} \\
\left(\Delta P C_{t}\right)\end{array}$ & $\mathrm{R}^{2}$ \\
\hline \multirow[t]{4}{*}{ Indonesia } & 1983-1999 & -0.464 & $0.075^{*}$ & -0.260 & $-0.357 * * *$ & {$[-0.704,-0.010]$} & 0.64 \\
\hline & & $(0.210)$ & $(0.050)$ & $(0.225)$ & $(0.085)$ & & \\
\hline & $2000-2007$ & $0.649^{* *}$ & -0.086 & $0.814^{* * *}$ & $-0.728^{* * *}$ & {$[-5.489,4.033]$} & 0.95 \\
\hline & & $(0.167)$ & $(0.024)$ & $(0.113)$ & $(0.084)$ & & \\
\hline \multirow[t]{4}{*}{ Korea } & 1973-1996 & $0.932^{* * *}$ & 0.004 & $0.803^{* * *}$ & $-0.647 * * *$ & {$[-0.908,-0.386]$} & 0.89 \\
\hline & & $(0.085)$ & $(0.035)$ & $(0.140)$ & $(0.091)$ & & \\
\hline & $1997-2007$ & 0.303 & $0.073^{*}$ & $1.015^{*}$ & $-0.560 * *$ & {$[-5.276,4.155]$} & 0.52 \\
\hline & & $(0.250)$ & $(0.050)$ & $(0.634)$ & $(0.225)$ & & \\
\hline \multirow[t]{4}{*}{ Malaysia } & 1962-1997 & $0.818^{* * *}$ & $0.154^{*}$ & $0.756^{* * *}$ & $-0.136^{* * *}$ & {$[-0.274,0.001]$} & 0.80 \\
\hline & & $(0.131)$ & $(0.102)$ & $(0.151)$ & $(0.048)$ & & \\
\hline & $1998-2007$ & $0.628^{* * *}$ & -0.002 & $0.689^{* *}$ & 0.371 & {$[-2.740,3.481]$} & 0.86 \\
\hline & & $(0.111)$ & $(0.223)$ & $(0.280)$ & $(0.411)$ & & \\
\hline \multirow[t]{4}{*}{ Philippines } & $1962-1997$ & $0.611^{* * *}$ & $0.024^{*}$ & $0.458^{* * *}$ & $-0.296 * * *$ & {$[-0.459,-0.133]$} & 0.81 \\
\hline & & $(0.151)$ & $(0.016)$ & $(0.150)$ & $(0.062)$ & & \\
\hline & $1998-2007$ & $0.862^{* * *}$ & -0.002 & $0.877^{* * *}$ & 0.084 & {$[-3.126,3.294]$} & 1.00 \\
\hline & & $(0.050)$ & $(0.005)$ & $(0.162)$ & $(0.194)$ & & \\
\hline \multirow[t]{4}{*}{ Singapore } & 1969-1996 & $0.799 * * *$ & -0.016 & $0.882^{* * *}$ & 0.136 & {$[-0.099,0.371]$} & 0.96 \\
\hline & & $(0.113)$ & $(0.270)$ & $(0.146)$ & $(0.111)$ & & \\
\hline & $1997-2007$ & $0.786^{* *}$ & 0.225 & $0.968^{* * *}$ & 0.286 & {$[-4.315,4.887]$} & 0.94 \\
\hline & & $(0.223)$ & $(0.276)$ & $(0.252)$ & $(0.214)$ & & \\
\hline \multirow[t]{4}{*}{ Thailand } & $1968-1996$ & $0.758^{* * *}$ & -0.020 & $0.775^{* * *}$ & $-0.178^{* * *}$ & {$[-0.294,-0.062]$} & 0.94 \\
\hline & & $(0.093)$ & $(0.021)$ & $(0.174)$ & $(0.045)$ & & \\
\hline & 1997-2007 & $0.725^{* * *}$ & -0.027 & $1.093^{* * *}$ & -0.106 & {$[-0.570,0.359]$} & 0.74 \\
\hline & & $(0.191)$ & $(0.034)$ & $(0.308)$ & $(0.086)$ & & \\
\hline
\end{tabular}

Notes: The dependent variable is the current account, $C A_{t}$. All estimations include constant terms, although we do not report the estimated constants here. The asterisks ***, **, and * indicate the 1\%, 5\%, and $10 \%$ significance levels, respectively, for the one-sided tests. The numbers in parentheses are the heteroskedasticity-robust standard errors. The $95 \%$ confidence interval (CI) of the coefficient of $\Delta P C_{t}$ is computed based on 10,000 bootstrapping repetitions. 
FIGURE 1

Test for the Structural Change of $\Delta P C_{t-1}$
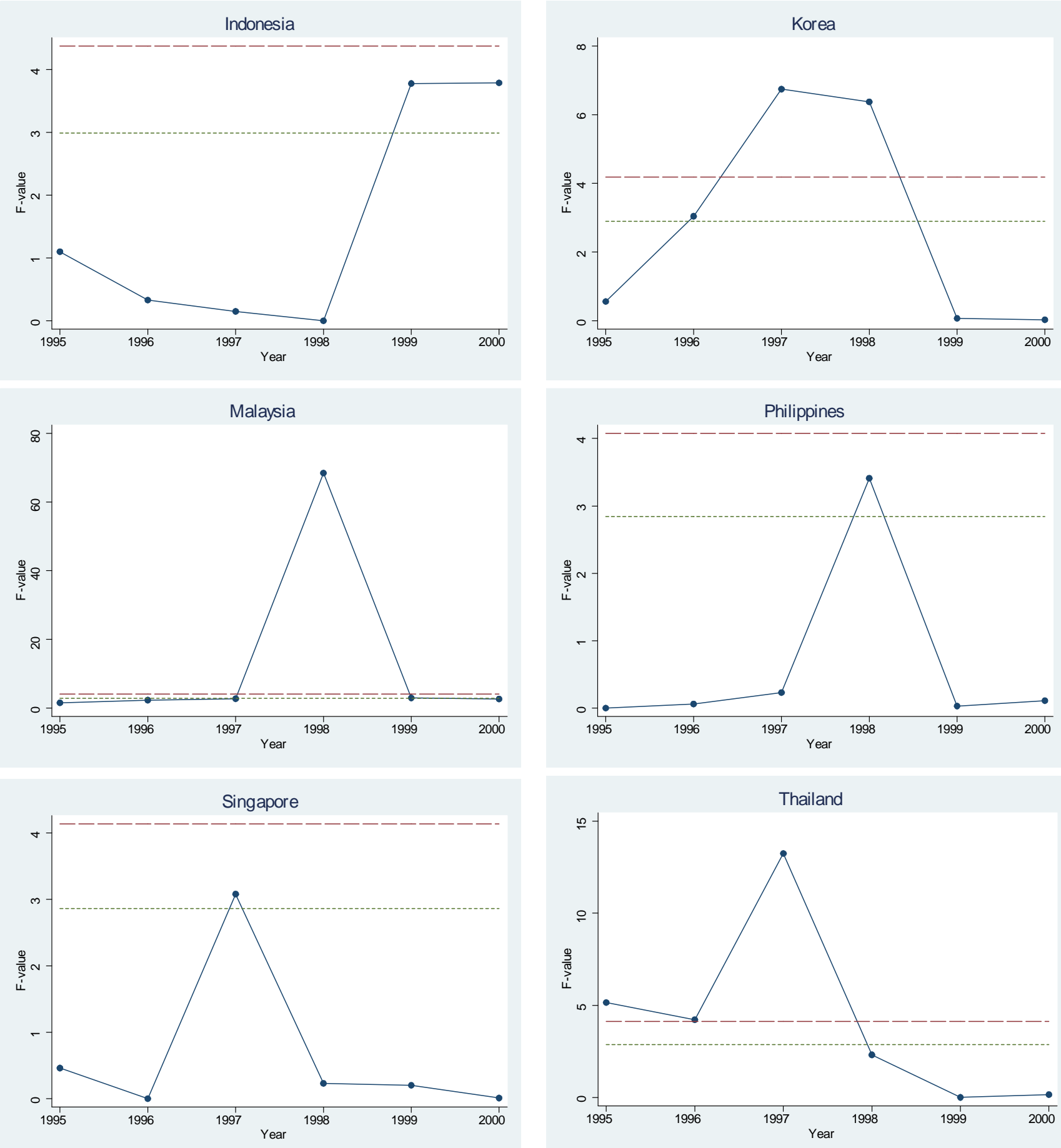

Notes: Each of the F-values is calculated under the null hypothesis that the coefficient of $\Delta P C_{t-1}$ is not structurally changed after a given year. The long- and short-dash lines indicate the 5\% and $10 \%$ significance levels, respectively. 
FIGURE 2

Bootstrapping Distributions of the Coefficient of $\Delta P C_{t-1}$
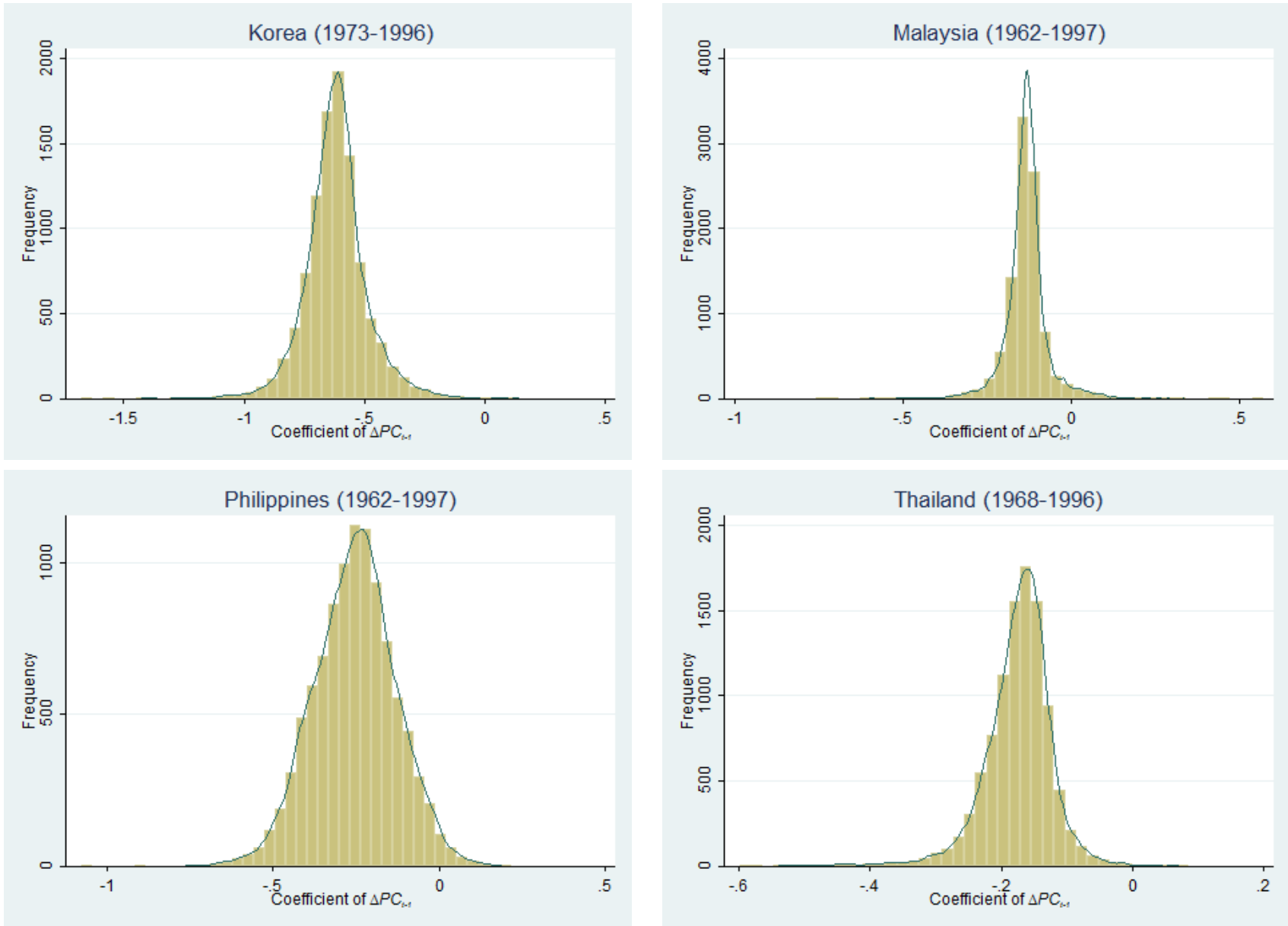

Notes: The distributions are created from 10,000 bootstrapping repetitions. 


\title{
Online Appendix \\ Collateral Constraints and the Current Account: Theory and Evidence
}

\author{
Takuma Kunieda* \\ Keisuke Okada ${ }^{\dagger}$ \\ Akihisa Shibata ${ }^{\ddagger}$ \\ Kwansei Gakuin University \\ Kansai University \\ Kyoto University
}

\section{A. Proof of Proposition 1}

To derive the current account dynamics, we aggregate the consumption functions over all of the agents. From Eqs. (12), (13), and (16) the aggregate consumption function is given by the following:

$$
C_{t}=(1-\beta)\left[Z_{t}-F R_{t}+R \times F R_{t-1}+q_{t} \bar{X}+R\left(F_{t-1}-F R_{t-1}\right)+(1-\lambda) \sum_{j=0}^{\infty} R^{-j} \pi_{t+j}\right]
$$

where $C_{t}=\lambda c_{t}+(1-\lambda) c_{t}^{*}, Z_{t}=\lambda y_{t}+(1-\lambda) y_{t}^{*}-g_{t}-(1-\lambda) I_{t}^{*}$, and $F_{t-1}-F R_{t-1}=$ $-\left(\lambda b_{t-1}+(1-\lambda) b_{t-1}^{*}\right)$. Here, $F_{t-1}$ is the net foreign assets held by the country at time $t-1$. The first difference of Eq. (A.1) is obtained as follows:

$$
\Delta C_{t}=(1-\beta)\left[\Delta Z_{t}+\Delta q_{t} \bar{X}+R \Delta F_{t-1}-\Delta F R_{t}+(1-\lambda) \sum_{j=0}^{\infty} R^{-j} \Delta \pi_{t+j}\right]
$$

By linearizing $\sum_{j=0}^{\infty} R^{-j} \Delta \pi_{t+j}$ around the steady state, we obtain $\sum_{j=0}^{\infty} R^{-j} \Delta \pi_{t+j}=-\hat{x}^{*} \Delta q_{t}$, where $\hat{x}^{*}$ is the land held by a saver in the steady state. By using this equation, Eq. (A.2)

\footnotetext{
${ }^{*}$ School of Economics, Kwansei Gakuin University, 1-155 Uegahara Ichiban-cho, Nishinomiya, Hyogo 662-8501, Japan. Phone +81-798-54-6204, Fax +81-798-51-0944, E-mail tkunieda@kwansei.ac.jp

$\dagger$ Faculty of Economics, Kansai University, 3-3-35 Yamate-cho, Suita-shi, Osaka 564-8680, JAPAN, Phone: +81-6-6368-0623, Fax: +81-6-6339-7704, E-mail: k_okada@kansai-u.ac.jp

$\ddagger$ Institute of Economic Research, Kyoto University, Yoshida-Honmachi, Sakyo-ku, Kyoto 606-8501, JAPAN, Phone: +81-75-753-7126, Fax: +81-75-753-7198, E-mail: shibata@kier.kyoto-u.ac.jp
} 
is reduced to

$$
\Delta C_{t}=(1-\beta)\left[\Delta Z_{t}+\left(\bar{X}-(1-\lambda) \hat{x}^{*}\right) \Delta q_{t}+R \Delta F_{t-1}-\Delta F R_{t}\right]
$$

Meanwhile, it follows from the national income identity that ${ }^{1}$

$$
C A_{t}=R C A_{t-1}+\Delta Z_{t}-\Delta C_{t},
$$

where $C A_{t}=\Delta F_{t}$ is the current account at time $t$. From Eqs. (A.3) and (A.4), we obtain a dynamic equation with respect to the current account:

$$
C A_{t}=\beta R C A_{t-1}+(1-\beta) \Delta F R_{t}+\beta \Delta Z_{t}-(1-\beta)\left(\bar{X}-(1-\lambda) \hat{x}^{*}\right) \Delta q_{t} .
$$

Linearizing $R b_{t}=q_{t+1} x_{t}$ around the steady state, we have

$$
R\left(b_{t}-\hat{b}\right)=\hat{x}\left(q_{t+1}-\hat{q}\right)+\hat{q}\left(x_{t}-\hat{x}\right) .
$$

By taking the first difference of this equation, it follows that

$$
R \Delta b_{t}=\hat{x} \Delta q_{t+1}+\hat{q} \Delta x_{t}
$$

Because $\bar{X}=\lambda x_{t}+(1-\lambda) x_{t}^{*}$, Eq. (A.5) becomes

$$
C A_{t}=\beta R C A_{t-1}+(1-\beta) R \Delta F R_{t-1}+\beta \Delta Z_{t}-(1-\beta) \lambda \hat{x} \Delta q_{t} .
$$

From Eqs. (4), (14), and (16), we have $G_{1}^{\prime}\left(\left(\bar{X}-\lambda x_{t}\right) /(1-\lambda)\right) x_{t}=R \beta a x_{t-1}$. By linearizing this equation around the steady state, we have $x_{t}-\hat{x}=\Phi\left(x_{t-1}-\hat{x}\right)$, where

\footnotetext{
${ }^{1}$ We should note that the national income identity is $Z_{t}+R F_{t-1}=F_{t}+C_{t}$.
} 
$\Phi:=\beta R a /\left[\beta R a-\hat{G}_{1}^{\prime \prime} \hat{x} \lambda /(1-\lambda)\right]$. Then, it follows that

$$
\Delta x_{t}=\Phi \Delta x_{t-1}
$$

and thus

$$
\Delta x_{t}=\Phi^{t-1} \Delta x_{1}
$$

From Eq. (4), we have $(1-\tau) G_{1}^{\prime}\left(\left(\bar{X}-\lambda x_{t}\right) /(1-\lambda)\right)=R q_{t}-q_{t+1}$, which is expanded around the steady state as follows:

$$
-\frac{\lambda(1-\tau)}{1-\lambda} \hat{G}_{1}^{\prime \prime}\left(x_{t}-\hat{x}\right)=R\left(q_{t}-\hat{q}\right)-\left(q_{t+1}-\hat{q}\right)
$$

where $\hat{G}_{1}^{\prime \prime}=G_{1}^{\prime \prime}\left(\hat{x}^{*}\right)$. From this, we obtain

$$
\Delta q_{t+1}=R \Delta q_{t}+\frac{\lambda(1-\tau)}{1-\lambda} \hat{G}_{1}^{\prime \prime} \Delta x_{t}
$$

By substituting Eq. (A.8) into Eq. (A.9), we have

$$
\Delta q_{t+1}=R \Delta q_{t}+\frac{\lambda(1-\tau)}{1-\lambda} \hat{G}_{1}^{\prime \prime} \Phi^{t-1} \Delta x_{1}
$$

The solution of Eq. (A.10) is given by the following:

$$
\Delta q_{t}=\left(\frac{\Delta q_{1}}{\Phi}-\lambda \tilde{\Phi}\right) \Phi R^{t-1}+\lambda \tilde{\Phi} \Phi^{t}
$$

where $\tilde{\Phi}=(1-\tau) \hat{G}_{1}^{\prime \prime} \Delta x_{1} /\left[(1-\lambda)\left(\Phi^{2}-R \Phi\right)\right]$. It must hold that $\Delta q_{1}=\lambda \tilde{\Phi} \Phi$ so that the transversality condition can be satisfied. Therefore, we obtain

$$
\Delta q_{t}=\lambda \tilde{\Phi} \Phi^{t}
$$

From Eqs. (A.9) and (A.12), we have $\Delta x_{t}=\Delta x_{1} /\left(\lambda \tilde{\Phi} \Phi^{2}\right) \Delta q_{t+1}$. From the latter equation 
and Eq. (A.6), we obtain the following equation:

$$
\hat{x} \Delta q_{t+1}=\frac{R \lambda \tilde{\Phi} \Phi^{2} \hat{x}}{\lambda \tilde{\Phi} \Phi^{2} \hat{x}+\hat{q} \Delta x_{1}} \Delta b_{t} .
$$

Substituting Eq. (A.13) into Eq. (A.7), we obtain

$$
C A_{t}=\beta R C A_{t-1}+(1-\beta) \Delta F R_{t}+\beta \Delta Z_{t}-(1-\beta) \lambda^{2} \Psi \hat{x} \Delta b_{t-1},
$$

where $\Psi:=R \tilde{\Phi} \Phi^{2} /\left(\lambda \tilde{\Phi} \Phi^{2} \hat{x}+\hat{q} \Delta x_{1}\right)$. Because the increase in loans to each borrower contributes to the increase in aggregate private credit, we have $\lambda \Delta b_{t}:=\Delta P C_{t}$. By substituting this equation into (A.14), we obtain

$$
C A_{t}=\beta R C A_{t-1}+(1-\beta) \Delta F R_{t}+\beta \Delta Z_{t}-(1-\beta) \Psi \lambda \hat{x} \Delta P C_{t-1}
$$

\section{B. Binding Credit Constraints}

The claim that there exists $T$ such that from time $T$ onwards, Eq. (9) is always binding is proven taking two steps. Step 1 claims that each borrower faces a credit constraint at least once over her lifetime. Step 2 claims that if a borrower faces a credit constraint at time $T$, then the credit constraints are binding from $T$ onward.

First, step 1 is proven by contradiction. Suppose that Eq. (9) is never binding. Then, $\phi_{t}=0$ for all $t \geq 0$, and thus the Euler equation for a borrower becomes

$$
c_{t+1}=\beta R c_{t},
$$

and the dynamic equation for the land price is given by

$$
q_{t+1}=R q_{t}-a(1-\tau)
$$


From Eq. (B.2) and the transversality condition, $q_{t}$ must be constant for all $t \geq 0$ and is given by

$$
q_{t}=\frac{a(1-\tau)}{R-1}
$$

From this equation, Eq. (4) is reduced to

$$
G_{1}^{\prime}\left(x_{t}^{*}\right)=a,
$$

which implies that both $x_{t}$ and $x_{t}^{*}$ are constant. Then, the borrower's budget constraint (8) becomes

$$
c_{t}+R b_{t-1}=a(1-\tau) \tilde{x}+b_{t},
$$

where $\tilde{x}:=\bar{X} / \lambda-(1-\lambda) G_{1}^{-1}(a) / \lambda$. From Eqs. (B.1) and (B.3) and the transversality condition, we can obtain the dynamics of $b_{t}$ as follows:

$$
b_{t}=\frac{\beta c_{0}}{\beta-1}(\beta R)^{t}+\frac{a(1-\tau) \tilde{x}}{R-1},
$$

where $c_{0}$ is the initial value of consumption. Because $\beta<1$ and $R \beta<1, b_{t}$ is increasing and converges to $a(1-\tau) \tilde{x} /(R-1)$. However, this result is a contradiction because the right-hand side of Eq. (9) is equal to $a(1-\tau) \tilde{x} / R(R-1)<a(1-\tau) \tilde{x} /(R-1)$.

Next, we will show step 2. Suppose that the claim of step 2 does not hold. More concretely, suppose that Eq. (9) is not binding at time $t$ when it is binding at time $t-1$. In this case, we have the Euler equations at time $t-1$ and $t$, respectively, as follows:

$$
\begin{aligned}
c_{t} & =\frac{(1-\tau) a \beta}{u_{t-1}} c_{t-1} \\
c_{t+1} & =\beta R c_{t},
\end{aligned}
$$

which implies that $u_{t}$ becomes constant and is given by $\tilde{u}:=(1-\tau) a / R$. From Eq. (4), $x_{t}^{*}$ and $x_{t}$ are constant and given by $\tilde{x}^{*}:=G_{1}^{-1}(a)$ and $\tilde{x}:=\bar{X} / \lambda-(1-\lambda) G_{1}^{-1}(a) / \lambda$, 
respectively.

Because the first equality of Eq. (16) holds whether Eq. (9) is binding or not, it follows from Eq. (16), Eq. (B.5) and $q_{t+1}=R q_{t}-(1-\tau) a$ that $b_{t}=q_{t} \tilde{x}-\beta a(1-\tau) x_{t-1}$. From the last, however, we have

$$
\begin{aligned}
R b_{t}-q_{t+1} \tilde{x} & =\left(\lambda \tilde{x}-\beta R \lambda x_{t-1}\right)(1-\tau) a / \lambda \\
& >(\lambda \tilde{x}-\beta R \bar{X})(1-\tau) a / \lambda \\
& =\left[(1-\beta R) \bar{X} /(1-\lambda)-G_{1}^{\prime-1}(a)\right](1-\tau)(1-\lambda) a / \lambda>0
\end{aligned}
$$

where the last inequality comes from Eq. (6). This result is a contradiction. From mathematical induction, we have a desired conclusion.

\section{Proof of Proposition 2 and Related Equations}

\section{C.1. Derivations of Related Equations}

To exclude economically meaningless solutions, we impose technical conditions similar to

Eq. (6): $\underline{a}>R \beta \underline{a}>G_{1}^{\prime}((1-R \beta) \bar{X} /(1-\lambda))$ and assume that Eq. (20) is binding as in section II.

From the first-order conditions of the borrower's maximization problem, we obtain

$$
\frac{q_{t}}{c_{t}}=\beta E_{t}\left[\frac{(1-\tau) a_{t+1}+q_{t+1}}{c_{t+1}}\right]+\frac{E_{t}\left(q_{t+1}\right)}{R}\left[\frac{1}{c_{t}}-\beta R E_{t}\left(\frac{1}{c_{t+1}}\right)\right] .
$$

This equation can be rewritten as

$$
\frac{E_{t}\left(u_{t}\right)}{c_{t}}=\beta\left[(1-\tau) a+(1-\tau) \gamma_{t}^{2}+\gamma_{t}^{1}\right] E_{t}\left[\frac{1}{c_{t+1}}\right]
$$


which is Eq. (21) or, equivalently,

$$
\frac{1}{c_{t}}=\frac{\beta \tilde{a}}{E_{t}\left(u_{t}\right)} E_{t}\left[\frac{1}{c_{t+1}}\right]
$$

where $\tilde{a}=(1-\tau) a+(1-\tau) \gamma_{t}^{2}+\gamma_{t}^{1}$. Because Eq. (20) is binding, Eq. (19) yields

$$
1+E_{t}\left(u_{t}\right) \frac{x_{t}}{c_{t}}=x_{t-1} \times \frac{(1-\tau) a_{t}+q_{t}-E_{t-1}\left(q_{t}\right)}{c_{t}} .
$$

By taking an expectation for both sides of Eq. (C.2) given information at time $t-1$, we obtain

$$
E_{t-1}\left[1+E_{t}\left(u_{t}\right) \frac{x_{t}}{c_{t}}\right]=x_{t-1} \tilde{a} E_{t-1}\left[\frac{1}{c_{t}}\right] .
$$

Eq. (C.1) rewrites Eq. (C.3) as

$$
E_{t-1}\left[1+E_{t}\left(u_{t}\right) \frac{x_{t}}{c_{t}}\right]=\frac{x_{t-1} E_{t-1}\left(u_{t-1}\right)}{\beta c_{t-1}} .
$$

From Eq. (C.4) and the transversality condition, we obtain

$$
E_{t}\left(u_{t}\right) x_{t}(1-\beta)=\beta c_{t} .
$$

It follows from Eqs. (C.2) and (C.5) that

$$
c_{t}=(1-\beta)\left[(1-\tau) a_{t} x_{t-1}+\left[q_{t}-E_{t-1}\left(q_{t}\right)\right] x_{t-1}\right] .
$$

Eq. (C.6) is rewritten as

$$
c_{t}=(1-\beta)\left[(1-\tau) a_{t} x_{t-1}+q_{t} x_{t-1}-R b_{t-1}\right] .
$$

This equation is Eq. (27).

From Eqs. (24) and (25), we obtain the intra-temporal optimality condition in the land 
market as follows:

$$
\frac{(1-\tau) G_{1}^{\prime}\left(x_{t}^{*}\right)}{E_{t}\left(w_{t}\right)}=R
$$

where $w_{t}=q_{t}-\left(q_{t+1}+\gamma_{t}\right) / R$. Likewise, the intra-temporal optimality condition in the capital market is given by

$$
(1-\tau) G_{2}^{\prime}\left(k_{t}^{*}\right)=R+\delta-1 .
$$

From Eq. (24) we have

$$
(\beta R)^{s} c_{t}^{*}=\frac{1}{E_{t}\left[1 / c_{t+s}^{*}\right]}
$$

We will use this equation later on. Before deriving the consumption function of a saver, we define the steady state of this stochastic model, which is used when linearizing the model. From Eqs. (C.5), (C.6), and (C.8), it follows that

$$
\left[(1-\tau) G_{1}^{\prime}\left(\frac{\bar{X}-\lambda x_{t}}{1-\lambda}\right)+\gamma_{t}\right] x_{t}=\beta R\left[(1-\tau) a_{t}+q_{t}-E_{t-1}\left(q_{t}\right)\right] x_{t-1}
$$

Taking an expectation for both sides of this equation, we obtain

$$
E_{t-1}\left[\left((1-\tau) G_{1}^{\prime}\left(\frac{\bar{X}-\lambda x_{t}}{1-\lambda}\right)+\gamma_{t}\right) x_{t}\right]=\beta R(1-\tau) a x_{t-1} .
$$

From Eq. (C.8), it follows that

$$
(1-\tau) G_{1}^{\prime}\left(\frac{\bar{X}-\lambda x_{t}}{1-\lambda}\right)+\gamma_{t}=R E_{t}\left(u_{t}\right)
$$

where

$$
u_{t}=q_{t}-\frac{q_{t+1}}{R}
$$

From Eqs. (C.11)-(C.13), the steady state values of $x_{t}, u_{t}$, and $q_{t}$ with $E_{t}\left(a_{t}\right)=a$ are given 
by $\hat{x}, \hat{u}$, and $\hat{q}$ such that

$$
\begin{aligned}
& \beta R(1-\tau) a=E_{t-1}\left[\left((1-\tau) G_{1}^{\prime}\left(\frac{\bar{X}-\lambda \hat{x}}{1-\lambda}\right)+\hat{\gamma}\right)\right] \\
&=\left((1-\tau) G_{1}^{\prime}\left(\frac{\bar{X}-\lambda \hat{x}}{1-\lambda}\right)+\hat{\gamma}\right) \\
&(1-\tau) G_{1}^{\prime}\left(\frac{\bar{X}-\lambda \hat{x}}{1-\lambda}\right)+\hat{\gamma}=R \hat{u}
\end{aligned}
$$

and

$$
\hat{u}=\left(1-\frac{1}{R}\right) \hat{q}
$$

where $\hat{\gamma}$ is $\gamma_{t}$ 's value when the economy is in the stationary state, which is constant because all variables exhibit stationary distributions. Note that $\hat{x}, \hat{u}$, and $\hat{q}$ are elements of the stationary state in this stochastic model. When linearizing the model, we do it around the steady state that we have derived.

From Eq. (23), we have

$$
\begin{aligned}
1+\frac{q_{t} x_{t}^{*}+k_{t}^{*}-b_{t}^{*}}{c_{t}^{*}} & =\frac{1}{c_{t}^{*}}\left[(1-\tau) G_{1}^{\prime}\left(x_{t-1}^{*}\right) x_{t-1}^{*}+q_{t} x_{t-1}^{*}+(1-\tau) G_{2}^{\prime}\left(k_{t-1}^{*}\right) k_{t-1}^{*}+(1-\delta) k_{t-1}^{*}\right. \\
& \left.-R b_{t-1}^{*}+\tilde{\pi}_{t-1}\right],
\end{aligned}
$$

where $\tilde{\pi}_{t-1}=(1-\tau)\left(G_{1}\left(x_{t-1}^{*}\right)-G_{1}^{\prime}\left(x_{t-1}^{*}\right) x_{t-1}^{*}\right)+(1-\tau)\left(G_{2}\left(k_{t-1}^{*}\right)-G_{2}^{\prime}\left(k_{t-1}^{*}\right) k_{t-1}^{*}\right)$. Taking an expectation for both sides of this equation given information at time $t-1$, we obtain

$$
\begin{aligned}
E_{t-1}\left[1+\frac{q_{t} x_{t}^{*}+k_{t}^{*}-b_{t}^{*}}{c_{t}^{*}}\right] & =E_{t-1}\left[\frac{1}{c_{t}^{*}}\right]\left[(1-\tau) G_{1}^{\prime}\left(x_{t-1}^{*}\right) x_{t-1}^{*}+\left(E_{t-1}\left(q_{t}\right)+\gamma_{t-1}\right) x_{t-1}^{*}\right. \\
& \left.+(1-\tau) G_{2}^{\prime}\left(k_{t-1}^{*}\right) k_{t-1}^{*}+(1-\delta) k_{t-1}^{*}-R b_{t-1}^{*}+\tilde{\pi}_{t-1}\right]
\end{aligned}
$$

Applying Eqs. (24)-(26) to this equation yields

$$
E_{t-1}\left[1+\frac{q_{t} x_{t}^{*}}{c_{t}^{*}}+\frac{k_{t}^{*}}{c_{t}^{*}}-\frac{b_{t}^{*}}{c_{t}^{*}}\right]=\frac{1}{\beta}\left(\frac{q_{t-1} x_{t-1}^{*}}{c_{t-1}^{*}}+\frac{k_{t-1}^{*}}{c_{t-1}^{*}}-\frac{b_{t-1}^{*}}{c_{t-1}^{*}}\right)+\tilde{\pi}_{t-1} E_{t-1}\left[\frac{1}{c_{t}^{*}}\right] .
$$


Define $J_{t}:=\left(q_{t} x_{t}^{*}+k_{t}^{*}-b_{t}^{*}\right) / c_{t}^{*}$. By applying the law of iterated expectations to Eq. (C.14), it follows that

$$
\begin{aligned}
& J_{t}=\beta+\beta^{2}+\cdots+\beta^{s}+\beta^{s} E_{t}\left(J_{t+s}\right) \\
& -E_{t}\left[\beta \frac{\tilde{\pi}_{t}}{c_{t+1}^{*}}+\beta^{2} \frac{\tilde{\pi}_{t+1}}{c_{t+2}^{*}}+\cdots+\beta^{s} \frac{\tilde{\pi}_{t+s-1}}{c_{t+s}^{*}}\right] .
\end{aligned}
$$

By using Eq. (24) and applying the law of iterated expectations again, it follows that

$$
\begin{aligned}
& E_{t}\left[\beta \frac{\tilde{\pi}_{t}}{c_{t+1}^{*}}+\beta^{2} \frac{\tilde{\pi}_{t+1}}{c_{t+2}^{*}}+\cdots+\beta^{s} \frac{\tilde{\pi}_{t+s-1}}{c_{t+s}^{*}}\right] \\
& =E_{t}\left[\beta^{2} R E_{t+1}\left[\frac{\tilde{\pi}_{t}}{c_{t+2}^{*}}\right]+\beta^{2} \frac{\tilde{\pi}_{t+1}}{c_{t+2}^{*}}+\cdots+\beta^{s} \frac{\tilde{\pi}_{t+s-1}}{c_{t+s}^{*}}\right] \\
& =E_{t}\left[(\beta R)^{2}\left(\frac{\tilde{\pi}_{t}}{R}+\frac{\tilde{\pi}_{t+1}}{R^{2}}\right) \frac{1}{c_{t+2}^{*}}+\beta^{3} \frac{\tilde{\pi}_{t+2}}{c_{t+3}^{*}}+\cdots+\beta^{s} \frac{\tilde{\pi}_{t+s-1}}{c_{t+s}^{*}}\right] \\
& =E_{t}\left[(\beta R)^{3} E_{t+2}\left[\left(\frac{\tilde{\pi}_{t}}{R}+\frac{\tilde{\pi}_{t+1}}{R^{2}}\right) \frac{1}{c_{t+3}^{*}}\right]+\beta^{3} \frac{\tilde{\pi}_{t+2}}{c_{t+3}^{*}}+\cdots+\beta^{s} \frac{\tilde{\pi}_{t+s-1}}{c_{t+s}^{*}}\right] \\
& =E_{t}\left[(\beta R)^{3}\left(\frac{\tilde{\pi}_{t}}{R}+\frac{\tilde{\pi}_{t+1}}{R^{2}}+\frac{\tilde{\pi}_{t+2}}{R^{3}}\right) \frac{1}{c_{t+3}^{*}}+\cdots+\beta^{s} \frac{\tilde{\pi}_{t+s-1}}{c_{t+s}^{*}}\right] \\
& \vdots \\
& =E_{t}\left[\frac{(\beta R)^{s}}{c_{t+s}^{*}} \sum_{j=1}^{s} \tilde{\pi}_{t+j-1} / R^{j}\right] \\
& =\frac{1}{c_{t}^{*}} E_{t}\left[\frac{1}{c_{t+s}^{*}} \sum_{j=1}^{s} \tilde{\pi}_{t+j-1} / R^{j}\right] / E_{t}\left[1 / c_{t+s}^{*}\right] \quad \because(\mathrm{C} .10) \\
& =\frac{1}{c_{t}^{*}}\left[E_{t}\left[\sum_{j=1}^{s} \tilde{\pi}_{t+j-1} / R^{j}\right]+C o v_{t}\left[\sum_{j=1}^{s} \tilde{\pi}_{t+j-1} / R^{j}, \frac{1}{c_{t+s}^{*}}\right] / E_{t}\left[1 / c_{t+s}^{*}\right]\right] .
\end{aligned}
$$

Therefore, $J_{t}$ can be rewritten as

$$
\begin{aligned}
& J_{t}=\beta+\beta^{2}+\cdots+\beta^{s}+\beta^{s} E_{t}\left(J_{t+s}\right) \\
& -\frac{1}{c_{t}^{*}}\left[E_{t}\left[\sum_{j=1}^{s} \tilde{\pi}_{t+j-1} / R^{j}\right]+\tilde{\gamma}_{t}(s)\right],
\end{aligned}
$$


where $\tilde{\gamma}_{t}(s)=\operatorname{Cov}_{t}\left[\sum_{j=1}^{s} \tilde{\pi}_{t+j-1} / R^{j}, 1 / c_{t+s}^{*}\right] / E_{t}\left[1 / c_{t+s}^{*}\right]$. Assuming that $\lim _{s \rightarrow \infty} \tilde{\gamma}_{t}(s)=\tilde{\gamma}_{t}$, the transversality condition $\lim _{s \rightarrow \infty} \beta^{s} E_{t}\left(J_{t+s}\right)=0$ tranforms Eq. (C.16) into

$$
J_{t}=\frac{\beta}{1-\beta}-\frac{1}{c_{t}^{*}}\left[E_{t}\left[\sum_{j=1}^{\infty} \tilde{\pi}_{t+j-1} / R^{j}\right]+\tilde{\gamma}_{t}\right]
$$

or, equivalently,

$$
q_{t} x_{t}^{*}+k_{t}^{*}-b_{t}^{*}+E_{t}\left[\sum_{j=1}^{\infty} \tilde{\pi}_{t+j-1} / R^{j}\right]+\tilde{\gamma}_{t}=\frac{\beta}{1-\beta} c_{t}^{*} .
$$

From Eqs. (23) and (C.17), it follows that

$$
c_{t}^{*}=(1-\beta)\left[(1-\tau) y_{t}^{*}-I_{t}^{*}+q_{t} x_{t-1}^{*}-R b_{t-1}^{*}+k_{t}^{*}+E_{t}\left[\sum_{j=1}^{\infty} \tilde{\pi}_{t+j-1} / R^{j}\right]+\tilde{\gamma}_{t}\right] \text {. }
$$

In Eq. (C.18), the use of Eqs. (C.8) and (C.9) computes $k_{t}^{*}+E_{t}\left[\sum_{j=1}^{\infty} \tilde{\pi}_{t+j-1} / R^{j}\right]$ as

$$
k_{t}^{*}+E_{t}\left[\sum_{j=1}^{\infty} \tilde{\pi}_{t+j-1} / R^{j}\right]=E_{t}\left[\sum_{j=0}^{\infty} \pi_{t+j} / R^{j}\right]
$$

where $\pi_{t+j}=(1 / R)\left[(1-\tau) y_{t+j+1}^{*}-I_{t+j+1}^{*}\right]-E_{t+j}\left(w_{t+j}\right) x_{t+j}^{*} \cdot{ }^{2}$ The linearization of $E_{t}\left[\sum_{j=0}^{\infty} \pi_{t+j} / R^{j}\right]$ around the steady state yields

$$
E_{t}\left[\sum_{j=0}^{\infty} \pi_{t+j} / R^{j}\right]=-\hat{x}^{*} q_{t}+\hat{x}^{*} E_{t}\left[\sum_{j=0}^{\infty} \gamma_{t+j} / R^{j+1}\right]+\left[(1-\tau) \hat{y}^{*}-\delta \hat{k}^{*}\right] /(R-1)
$$

\footnotetext{
${ }^{2}$ We use the same notation $\pi_{t+j}$ as in Eq. (13) in section II, although $w_{t+j}$ is applied in $\pi_{t+j}$ in Eq. (C.19) for simplicity.
} 
By inserting this equation into Eq. (C.18), we obtain

$$
\begin{aligned}
& c_{t}^{*}=(1-\beta)\left[(1-\tau) y_{t}^{*}-I_{t}^{*}+q_{t} x_{t-1}^{*}-R b_{t-1}^{*}-\hat{x}^{*} q_{t}\right. \\
& \left.+\hat{x}^{*} E_{t}\left[\sum_{j=0}^{\infty} \gamma_{t+j} / R^{j+1}\right]+\left[(1-\tau) \hat{y}^{*}-\delta \hat{k}^{*}\right] /(R-1)+\tilde{\gamma}_{t}\right] .
\end{aligned}
$$

which is Eq. (28).

\section{C.2. Aggregation}

Similarly to the proof of Proposition 1, Eqs. (27) and (28) yield aggregate consumption as follows:

$$
\begin{aligned}
& C_{t}=(1-\beta)\left[Z_{t}-F R_{t}+R \times F R_{t-1}+q_{t} \bar{X}+R\left(F_{t-1}-F R_{t-1}\right)-(1-\lambda) \hat{x}^{*} q_{t}\right. \\
& \left.+(1-\lambda) \hat{x}^{*} E_{t}\left[\sum_{j=0}^{\infty} \gamma_{t+j} / R^{j+1}\right]+(1-\lambda)\left[(1-\tau) \hat{y}^{*}-\delta \hat{k}^{*}\right] /(R-1)+(1-\lambda) \tilde{\gamma}_{t}\right] .
\end{aligned}
$$

We obtain the first difference of Eq. (C.20) as follows:

$$
\begin{aligned}
& \Delta C_{t}=(1-\beta)\left[\Delta Z_{t}+\lambda \hat{x} \Delta q_{t}+R \Delta F_{t-1}-\Delta F R_{t}\right. \\
& \left.+(1-\lambda) \hat{x}^{*} \Delta E_{t}\left[\sum_{j=0}^{\infty} \gamma_{t+j} / R^{j+1}\right]+(1-\lambda) \Delta \tilde{\gamma}_{t}\right] .
\end{aligned}
$$

On the equilibrium transition path, there are unobservable terms: $\Delta E_{t}\left[\sum_{j=0}^{\infty} \gamma_{t+j} / R^{j+1}\right]$ and $\Delta \tilde{\gamma}_{t}$. Therefore, we cannot estimate Eq. (C.21). However, in the stationary state where all variables exhibit stationary distributions, both $\Delta E_{t}\left[\sum_{j=0}^{\infty} \gamma_{t+j} / R^{j+1}\right]$ and $\Delta \tilde{\gamma}_{t}$ become 0 because $\gamma_{t}$ and $\tilde{\gamma}_{t}$ are constant. In what follows, we assume that the economy is in the stationary state. In this case, we obtain exactly the same equation as Eq. (A.7) from Eqs. 
(A.4) and (C.21) as follows:

$$
C A_{t}=\beta R C A_{t-1}+(1-\beta) \Delta F R_{t-1}+\beta \Delta Z_{t}-(1-\beta) \lambda \hat{x} \Delta q_{t} .
$$

\section{C.3. Proof of Proposition 2}

Linearizing $R b_{t}=E_{t}\left(q_{t+1}\right) x_{t}$ around the steady state, we have

$$
R\left(b_{t}-\hat{b}\right)=\hat{x}\left(E_{t}\left(q_{t+1}\right)-\hat{q}\right)+\hat{q}\left(x_{t}-\hat{x}_{t}\right)
$$

By taking the first difference of this equation, it follows that

$$
R \Delta b_{t}=\hat{x} \Delta E_{t}\left(q_{t+1}\right)+\hat{q} \Delta x_{t}
$$

Because $\Delta E_{t}\left(q_{t+1}\right)=0$ in the stationary state, Eq. (C.23) turns into

$$
R \Delta b_{t}=\hat{q} \Delta x_{t}
$$

Linearizing Eq. (C.12) around the steady state, we have

$$
-\frac{\lambda(1-\tau)}{1-\lambda} \hat{G}_{1}^{\prime \prime}\left(x_{t}-\hat{x}\right)=R\left(q_{t}-\hat{q}\right)-E_{t}\left(q_{t+1}\right)-\hat{q}
$$

By taking the first difference of this equation, it follows that

$$
\Delta E_{t}\left(q_{t+1}\right)=R \Delta q_{t}+\frac{\lambda(1-\tau)}{1-\lambda} \hat{G}_{1}^{\prime \prime} \Delta x_{t}
$$

Because $\Delta E_{t}\left(q_{t+1}\right)=0$ in the stationary state, Eq. (C.25) turns into

$$
\Delta x_{t}=-\frac{R(1-\lambda)}{\lambda(1-\tau) \hat{G}_{1}^{\prime \prime}} \Delta q_{t} .
$$


From Eqs. (C.24) and (C.26), we obtain

$$
\Delta q_{t}=\Omega \lambda \Delta b_{t}
$$

where $\Omega:=-(1-\tau) \hat{G}_{1}^{\prime \prime} /[(1-\lambda) \hat{q}]>0$. Because $\lambda \Delta b_{t}=\Delta P C_{t}$, the last equation becomes

$$
\Delta q_{t}=\Omega \Delta P C_{t}
$$

From Eqs. (C.22) and (C.27), it follows that

$$
C A_{t}=\beta R C A_{t-1}+(1-\beta) \Delta F R_{t-1}+\beta \Delta Z_{t}-(1-\beta) \lambda \hat{x} \Omega \Delta P C_{t}
$$

